FACULTAD DE CIENCIAS ECONÓMICAS

UNIVERSIDAD NACIONAL DE LA PLATA

\title{
Distribución de la población y migraciones internas en Argentina: sus determinantes individuales y regionales
}

\author{
Autor: Georgina Pizzolitto ${ }^{1}$ \\ Director: Dr. Alberto Porto
}

\begin{abstract}
Resumen
Aún a pesar de la importancia de los movimientos poblacionales en nuestro país, la revisión de la literatura existente sugiere una falta de esfuerzo en estudiar de manera integrada la magnitud y la dirección de los flujos migratorios, especialmente de los movimientos internos. Este trabajo además de describir el proceso migratorio en Argentina y caracterizar a la población migrante, estudia los determinantes de las decisiones de migración, con especial énfasis en las características individuales y regionales, así como la influencia de las políticas públicas provinciales. Utilizando datos de la Encuesta Permanente de Hogares, se estiman modelos para la probabilidad de ser migrante, tendiendo en cuenta estas características sociodemográficas y de las regiones de origen y destino de la población. Las estimaciones indican que las características individuales y los gastos en educación, vivienda pública y en programas de empleo que realizan las provincias son factores que determinan significativamente las decisiones de migración. El grado de urbanización y los recursos naturales de las provincias son las características regionales que más influencia tienen sobre los movimientos entre provincias.
\end{abstract}

Palabras Claves: Argentina, población, migraciones internas, políticas públicas Clasificación JEL: R12, R23, H3,H7

La Plata, Diciembre de 2006

\footnotetext{
${ }^{1}$ Email: gpizzolitto@yahoo.com.ar
} 


\section{Índice}

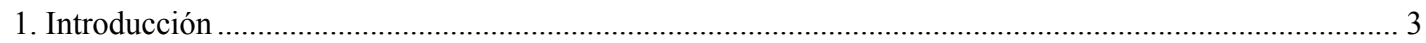

2. Teoría y antecedentes sobre los movimientos migratrios …....................................................... 4

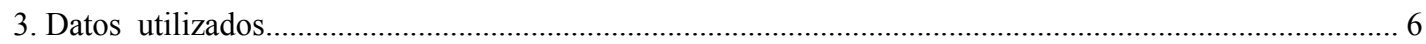

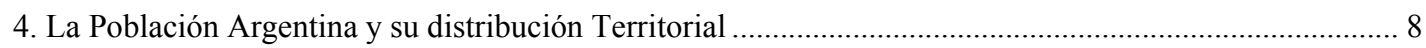

4.1. Composición población según su origen: población nativa y extranjera ....................................... 10

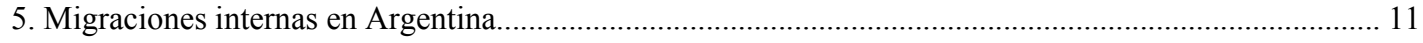

6. Características sociodemográficas de la población migrante ............................................................. 14

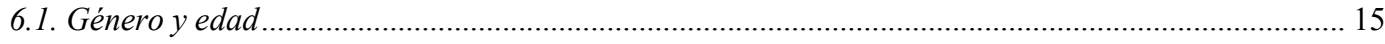

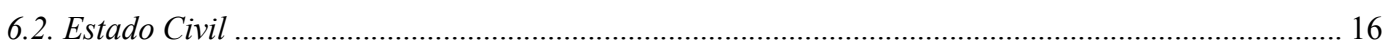

6.3. Composición y características de los hogares..................................................................................... 17

6.4. Características educacionales de la población migrante ............................................................... 18

6.5. Estado ocupacional y de la fuerza de trabajo ...................................................................................... 20

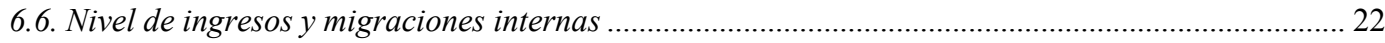

6.7. Pobreza y asistencia social de la población migrante y no migrante ............................................. 24

7. Marco Teórico y Metodología de estimación ............................................................................................ 25

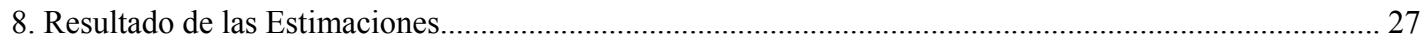

8.1 Características individuales y decisiones de migración ................................................................... 27

8.2. Características regionales, políticas públicas y decisiones de migración ...................................... 29

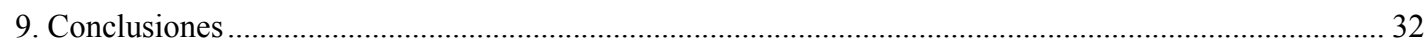

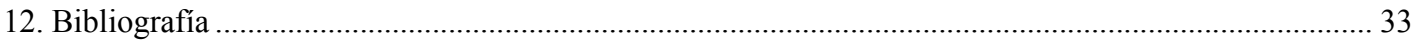

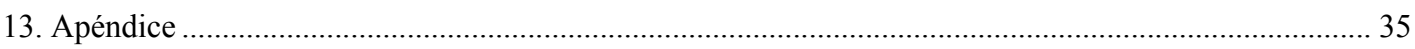




\section{INTRODUCCIÓN}

Las migraciones poblacionales continúan teniendo un importante rol en la composición demográfica y la configuración económica de la mayoría de los países del mundo. En nuestro país, tanto la inmigración masiva de extranjeros de mediados del siglo XIX, como las migraciones internas entre provincias y centros urbanos de las últimas décadas, son fenómenos que explican los patrones poblacionales existentes en nuestro país, así como también algunas de las disparidades económicas y de desarrollo existentes entre las regiones.

La observación de las tasas de migración internacional e interna en Argentina en el tiempo permite dar cuenta de la relevancia de estos hechos ubicando al país entre los de mayor movilidad poblacional. Si bien las tasas de migración han variado en respuesta a distintos fenómenos históricos según las épocas, el país se caracteriza por experimentar altas tasas migración y redistribución espacial de su población. Pero aún a pesar de la importancia de los movimientos poblacionales en nuestro país, la revisión de la literatura existente sugiere una falta de esfuerzo en estudiar de manera integrada la magnitud y la dirección de los flujos migratorios en nuestro país, especialmente los movimientos internos.

Desde el punto de vista económico, la decisión de migrar se basa en la maximización de utilidades: los individuos se trasladan si consideran que su utilidad se verá incrementada a partir de este movimiento. Así, cuando el fenómeno migratorio se formula como consecuencia de una serie de decisiones racionales que buscan la maximización de utilidades, los modelos tienen micro fundamentos los cuales permiten evaluar que características de los individuos influyen en la decisión de migrar o el efecto que tienen variables de tipo macroeconómicas, fiscales o regionales en esta decisión.

Entre las variables más utilizadas para explicar la decisión de migrar a otro país o localidad se pueden mencionar la búsqueda de mejores oportunidades laborales o bienestar económico, y razones relacionadas con la formación de capital humano. También pueden identificarse factores relacionados con el ciclo de vida, por ejemplo, para formar una familia, por jubilación o retiro; o por otras preferencias de tipo cultural o por las características climáticas y de desarrollo que el lugar de destino ofrece. Asimismo, las decisiones de migración pueden verse influidas por las políticas públicas de los gobiernos locales, que mediante decisiones presupuestarias afectan la calidad de los establecimientos educativos, los servicios de salud prestados a la comunidad, los programas de asistencia social o programas de vivienda pública, seguridad publica o menores tasas de impuestos o una menor presión tributaria etc..

Además de describir el proceso migratorio en Argentina y caracterizar a la población migrante, este trabajo tiene como objetivo estudiar los determinantes de las decisiones de migración, con especial énfasis en la relación con las características locales y de política publica. Para ello, se estiman modelos para la probabilidad de ser migrante, tendiendo en cuenta como variables explicativas las características socio-demográficas de los individuos y la relación con las diferencias regionales que se observan en el origen destino de los movimientos migratorios.

La organización de este trabajo es la siguiente: en la sección 2 se presentan una revisión de la literatura sobre el estudio de los movimientos migratorios y sus determinantes. En la sección 3 se describen los datos utilizados, las ventajas y limitaciones que presentan en el estudio de las migraciones internas en Argentina. En la sección 4 se describe la evolución y la distribución 
espacial de la población Argentina en el tiempo haciendo uso de los datos censales disponibles, mientras que en la sección 5 se realiza un breve análisis de las migraciones internas en nuestro país. En la sección 6 se describen algunas características socio-demográficas de la población argentina según su condición de migración interna. En la sección 7 se presenta el modelo a estimar sobre la decisión de migrar y la metodología de estimación, mientras que en la sección 8 se presenta los principales resultados de estas estimaciones. Finalmente, en la sección 9 se sintetizan las principales conclusiones del trabajo.

\section{TEORÍA Y ANTECEDENTES SOBRE LOS MOVIMIENTOS MIGRATRIOS}

Existe una extensa literatura sobre procesos migratorios en distintos países, que se diferencian según su abordaje o los múltiples aspectos que se investigan de este fenómeno. Entre las varias hipótesis propuestas para explicar los procesos migratorios, tres de ellas no deben dejar de mencionarse.

La primera de estas hipótesis se basa en la teoría neoclásica de la inversión en capital humano que cuenta entre sus principales exponentes los trabajos de Schultz y Sjaastad ${ }^{2}$. De acuerdo a esta corriente, las migraciones internas se analizan según los costos y retornos derivados de esa inversión en capital humano al migrar. Entre los retornos, se encuentran los diferenciales de salario que el migrante espera obtener de las mejores oportunidades laborales, mientras que los costos, lo determinan los gastos alojamiento y transporte, el tiempo de traslado o la adaptación al nuevo lugar de residencia. La existencia de estos costos implica que a pesar de que se observen diferencias sustanciales en los ingresos entre localidades, los mayores ingresos no necesariamente inducen un movimiento poblacional a esa región, si los costos asociados al traslado resultan superiores a los diferenciales de salario observados intertemporalmente ${ }^{3}$. Un aspecto enfatizado por Sjaastad (1962), es la relación entre los movimientos poblacionales. Según este autor, la inversión en migración es generalmente acompañada por inversiones complementarias, es decir, al igual que otras inversiones en capital humano, las migraciones tienen un alto retorno y estimula el crecimiento de las regiones de destino de la población migrante.

En relación a este ultimo aspecto, un enfoque más reciente, se ocupa de la relación que existe entre migraciones internas y el desarrollo económico en términos de selectividad de las personas ${ }^{4}$. Según esta hipótesis, los migrantes provienen de ciertos grupos: personas más dinámicas, tomadoras de riesgo y con capacidad para despegarse de su entorno tradicional y adaptarse a un ambiente no familiar y que se ven estimulados a moverse a centros que ofrecen mejores oportunidades económicas. Esta redistribución de la población, promueve como consecuencia el crecimiento e induce una mayor migración de individuos con esas mismas características. Dentro de esta rama de la literatura se destacan los trabajos de Kuznets (1957), Thomas (1977) y Sahora (1988). Entre los estudios recientes, Borjas (1994), estudia el impacto de la inmigración en la oferta de trabajo y los desbalance en los niveles de educación y la experiencia de los trabajadores que migran, mientras que en un estudio similar observa la tendencia de los migrantes menos educados a concentrarse en pequeñas áreas geográficas. Esta inmigración asociada a bajos salarios, disminuye el crecimiento económico y al aumentar las tasas de emigración, disminuye la fuerza de laboral local.

Una tercera explicación a las migraciones internas proviene de los trabajos realizados por Ravenstein (1892-1896) y Redford (1926), a partir de los cuales las fuerzas que determinan las migraciones se sintetizaron a través de las denominadas Leyes de Ravenstein. Estas leyes, que

2 Ver en particular Schultz (1962), Sjaastad (1962, 1978).

3 De acuerdo con esta teoría, los trabajadores adultos, tendrán menos disposición a movilizarse debido a que el periodo necesario para recuperar la inversión asociada al traslado.

4 Este enfoque, se asocia, debido al gran número de contribuciones realizadas, con la Escuela de Harvard. En particular, el trabajo de Simon Kuznets (1967). 
enuncian los factores de expulsión y atracción de la población, que se resumen de la siguiente manera: (i) las personas que viven en zonas rurales tiene una propensión más alta de emigrar que las personas que habitan en zonas urbanas, principalmente por factores asociados a la tenencia de la tierra y el acceso a bienes e infraestructura; (ii) los migrantes interurbanos tienden a trasladarse a las ciudades importantes; (iii) las migraciones disminuyen con la distancia; (iv) las mujeres predominan entre los migrantes de corta distancia; (v) las mejoras tecnológicas (especialmente en materia de transporte y comunicaciones) aumentan el volumen de migración; (vi) cada flujo migratorio se asocia a una corriente contraria que la compensa y (vii) los "motivos económicos" no necesariamente son los factores dominantes en las decisiones de migración". La enunciación de estas leyes sentó las bases para la mayoría de los estudios modernos sobre migración, muchos de los cuales se han limitado a contrastar la validez de estas leyes. Así, una importante rama de la literatura estudia la migración rural-urbana (por ejemplo, Todaro (1969) o Harris y Todaro (1970)), Lewis (1954) que estudia las migraciones como proveedoras de mano de obra en el sector manufacturero y Greenwood $(1995,2003)$ que sintetiza varios trabajos que validan las leyes de Ravenstein en el Reino Unido y Estados Unidos.

A pensar de las diferencias de estos enfoques, muchas de las variables explicativas que utilizan en sus modelos resultan idénticas. En principio, los tres enfoques presentados parten del supuesto de maximización de utilidades. Los individuos se trasladan a una nueva localidad si consideran que su bienestar se verá incrementado por tal movimiento. Esta hipótesis básica es lo suficientemente amplia como para permitir un amplio rango de factores que influyen sobre las decisiones individuales de migrar. Las oportunidades de ingresos y de empleo, la calidad ambiental, cualidades culturales, climáticas, costos monetarios y no monetarios de migrar y elementos de política publica, como la estructura fiscal o la prestación de servicios públicos, entre otros.

La relación funcional que existe entre una medida de la migración entre las localizaciones i y $\mathrm{j}$, $\mathrm{M}_{\mathrm{ij}}$, $\mathrm{y}$ varios determinantes de las migraciones, puede expresarse de la siguiente forma:

$$
M_{i j}=f\left(X_{11}, \ldots, X_{1 j}, \ldots, X_{n 1}, \ldots, X_{n j}, \varepsilon_{i j}\right)
$$

donde $X_{k j}$ representa el valor de las variables explicativas $k$ en la localización $j$,

Sin embargo, a pesar de estas similitudes, los estudios sobre migración varían en un número importante de aspectos: (i) la elección del flujo migratorio que estudian: intermunicipal, interprovincial, interregional; (ii) la definición de la variable migración (tasas brutas o tasas netas de migración entre localidades, entradas o salidas netas); (iii) las variables utilizadas como determinantes de las decisiones de migración; (iv) las especificaciones econométricas y las técnicas de estimación utilizadas (modelos lineales, logit y probits, logit multinomiales, etc.).

Entre las variables explicativas que comúnmente son incluidas en los estudios sobre migración pueden mencionarse, cuando se dispone de microdatos; las tasas de desempleo, diferenciales de salarios, ingreso familiar, distancia entre la región de origen y destino, indicadores del clima, costo de transporte, variables educativas, de género y edad de los migrantes. Algunos trabajos incluyen variables macroeconómicas, como las variables fiscales, el pago de transferencias intergubernamentales, beneficios de seguridad y asistencia social, seguros de desempleo o el monto de los impuestos, la presión tributaria, etc. Este trabajo busca examinar la migración interna estudiando la influencia en la decisión de migrar de las características de los migrantes, y su importancia diferencial dependiendo del lugar de origen del individuo y los múltiples destinos posibles entre los cuales decide migrar. 
Para otros países, los antecedentes son numerosos. En cuanto a las características individuales, Greenwood (1985), encuentra que las migraciones son mas frecuente entre los jóvenes que entre la población adulta, dado que migrar joven aumenta el horizonte temporal para el cálculo de los ingresos futuros esperados (Massey 1990). La educación también tiene un impacto significativo sobre las migraciones. Según Islam y Choudhury (1990), las personas más educadas pueden movilizarse con mayor facilidad y tienen mejor capacidad para adaptarse y conseguir un nuevo trabajo, respecto de los menos educados. En cuanto al estado civil de las personas, Greenwood (1975 y 1985) y Van Dijk (1989), encuentran que los individuos casados y con hijos tienen una menor probabilidad de migrar, debido al aumento en los costos asociados al traslado de toda la familia. Mincer (1978) en un estudio similar, encuentra que las mujeres casadas tienden a acompañar a sus esposos si estos deciden migrar por motivos económicos. Las diferencias de género no son un factor determinante en los estudios de migración. Katz (1998), muestra para los países de América Latina que la propensión a migrar de las mujeres es similar o levemente superior a la de los hombres, mientras que Bilsborrrow (1987) concluye que las mujeres migrantes son en promedio más jóvenes, y menos educadas y con una mayor probabilidad de ser solteras que su contraparte masculina.

Entre los trabajos que buscan determinar la presencia de migraciones inducidas por políticas públicas y detectar cual de estos elementos de política tiene mayor impacto sobre las decisiones de migrar de los individuos, pueden mencionarse los trabajos de Mills, Percy y Wilson (1983) y Foot y Milne (1984) quienes examinan el impacto combinado de los impuestos y los gastos públicos sobre las migraciones interprovinciales. Ambos estudios se basan en un indicador simple de la estructura fiscal, una medida del excedente fiscal igual al monto total de gastos públicos menos el monto total recaudado en concepto de impuestos. Hatton y Willianson (2002), encuentran para Estados Unidos, que las migraciones inducidas por políticas públicas se basan en diferencias en los niveles gastos asistenciales, seguros de desempleo y políticas de vivienda entre Estados.

En cuanto a la influencia de las características de las localidades de destino en la decisión de migración de las personas, la hipótesis básica indica que estas características implican beneficios adicionales a los diferenciales de ingreso que buscan obtener los individuos al migrar. Desde esta perspectiva, por ejemplo, una región rica en características puede tener salarios más bajos, pues las firmas atraen personas aprovechando estas condiciones. Alperovich, Bergsman, y Ehemann (1977), sugieren que el clima, el tamaño de las ciudades y las condiciones económicas, tienen un impacto positivo en los movimientos migratorios. Clark y Cosgrove (1991) concluyen que los factores que determinan una buena calidad de vida, junto con el crecimiento económico de las regiones determinan fuertemente los movimientos migratorios hacia esas regiones. Roxanne Ezzet-Lofstrom (2003), incluye características como el clima, la densidad poblacional, el desempleo, las tasas de crimen, la proximidad a centros costeros, la contaminación y varias variables relacionadas a la recreación (salas de cines, teatros, etc.), encontrando a estas variables significativas a la hora de explicar los movimientos entre ciudades de Estados Unidos.

Como se mencionó anteriormente, para el caso de argentina, no hay estudios previos acerca de que características de la población o de las regiones influyen los movimientos internos. En la siguiente sección se describirán brevemente los datos disponibles y sus limitaciones, para luego comenzar con el estudio de las migraciones internas en Argentina y las características sociodemográficas de la población migrante.

\section{Datos Utilizados}

Los datos sobre población, el flujo de inmigrantes y emigrantes interprovinciales, así como las tasas de inmigración y emigración por provincia presentados en la sección 2, fueron estimados a partir de datos de los Censos Nacionales de Población y Vivienda realizados por el Instituto 
Nacional de Estadística y Censos (INDEC). Para la estimación de los determinantes de las migraciones internas en Argentina, la base de datos se construyó combinando datos provinciales agregados provenientes de distintas fuentes de información y microdatos de la Encuesta Permanente de Hogares (EPH) correspondiente a la onda de Mayo de 2003.

La Encuesta Permanente de Hogares, incluye desde el año 1995 un módulo especial sobre migraciones, que permite identificar mediante una serie de preguntas a la población migrante, sean estos migrantes internos o internacionales ${ }^{5}$. Dos conceptos o definiciones de migrantes internos pueden realizarse a partir de estas preguntas. Por un lado, dado que la encuesta se pregunta acerca del lugar de nacimiento y el lugar de residencia actual, una definición posible es considerar como migrante interno a aquellos individuos que habitan, al momento de realizada la encuesta, en una provincia distinta a la de su nacimiento. Esta definición tiene la limitación que solo permite saber acerca de un único movimiento de las personas y no es posible saber el número de veces esta ha migrado. Tampoco es factible identificar a los individuos que han vivido fuera de su provincia natal y han retornado a la misma, luego de haber vivido en otra localidad.

Otra definición posible de migrante interno que puede obtenerse a partir de la EPH es la que considera como migrantes a aquellas personas que han vivido, fuera del área de relevamiento (aglomerado) por un período mayor a los 6 meses, es decir, que han vivido en otra provincia (distinta a la que habitan ahora) por un periodo mayor a 6 meses. La principal ventaja de esta forma de definir a los migrantes internos, reside en que permite captar las migraciones de tipo coyunturales o de corto plazo, por ejemplo por motivos de trabajo o estudio de los individuos. Por otro lado, dado que hace referencia al último movimiento migratorio de la persona, se puede identificar con claridad la provincia a la cual ha migrado recientemente (o en última oportunidad). Este hecho es importante al momento de estudiar los determinantes de las migraciones internas en argentina.

Si bien cada una de estas definiciones tiene sus ventajas y desventajas, ambas comparten una misma limitación: dado que la Encuesta Permanente de Hogares solo codifica el movimiento de personas entre provincias, el análisis de las migraciones internas en Argentina, queda reducido al estudio de las migraciones interprovinciales. Como consecuencia y debido a que la Encuesta Permanente de Hogares es realizada en aglomerados urbanos del país, estos datos no permiten aproximar con precisión las tasas de emigración e inmigración por provincias, motivo por el cual como se mencionó en el primer párrafo, se utilizan datos provenientes del Censo Nacional de Población. Se observa que la EPH subestima levemente las tasas de inmigración y emigración interna. Sin embargo, teniendo en cuenta que en general el movimiento migratorio se da hacia las ciudades más grandes o los principales aglomerados urbanos, la tasa de inmigración (es decir la tasa de llegada de personas a estos aglomerados en relación a la población de origen) es aproximada con bastante precisión. No ocurre lo mismo con la tasa de emigración, donde el movimiento de la población desde localidades más pequeñas o desde áreas rurales no es captado por la Encuesta permanente de hogares por no realizarse en estas localidades.

Los datos referidos a las características de las provincias, como la población, accidentes de tránsito, centros de salud, etc., se obtuvieron del Instituto Nacional de Estadística (INDEC), mientras que las series precipitaciones y temperatura medias anuales por provincias provienen del Servicio Meteorológico Nacional. Los datos sobre gastos en Educación, Vivienda, Programas de empleo y seguros de desempleo por provincia, se obtuvieron de las series históricas disponibles en la pagina web de la Dirección de Gasto Social. La variable sobre residuo fiscal, se obtuvo de estimaciones realizadas por Artana y Moskovits, disponibles en el libro "La distribución del Ingreso en Argentina", editado por Fiel (1999), mientras que los datos sobre recursos turísticos por provincias, se obtuvieron del trabajo realizado por Porto N. (2004): "Una aproximación al contenido factorial dominante de los recursos turísticos en Argentina”.

\footnotetext{
${ }^{5}$ En el Cuadro 1 del Apéndice se incluye el bloque de migraciones incluido en la Encuesta Permanente de Hogares.
} 
Todas las estadísticas descriptivas se realizaron sin tener en cuenta los hogares, en los cuales alguno de sus miembros, no han reportado su lugar de residencia anterior o año de migración. En cuanto a los modelos de migración, éstos fueron estimados sobre la población mayor a 28 años de edad, dado que se considera que a partir de esa edad se tiene autonomía en la decisión de migración y la acumulación de capital humano esta finalizada.

\section{LA Población ARgentina Y SU DISTRIbUCIÓn TeRritorial}

El primer Censo Nacional de población en Argentina fue realizado en 1869, año en el que se iniciaron los primeros estudios sobre población en nuestro país. Los temas poblacionales siempre han tenido una atención central en nuestro país. La alta concentración de la población así como el escaso número de pobladores, fue una constante preocupación por aquellos años y de los primeros gobiernos.

Según los datos del Censo 1869, había en Argentina 1.900.000 habitantes. Por entonces, las tasas de crecimiento poblacional eran muy bajas, según los datos del segundo censo nacional (realizado 26 años después) la población argentina apenas superaba los 4.000 .000 de habitantes. El mayor crecimiento poblacional se observa en el período 1914-1947, que corresponde a la llegada al país de inmigrantes europeos ocurrida entre 1850 y 1945 . A partir de este período, la tasa promedio de crecimiento anual de la población Argentina, decrece de manera constante, alcanzando en el último período intercensal la tasa de crecimiento poblacional más baja (10,1\% promedio anual, ver Cuadro 1). Según datos del último censo, la población total argentina es 36.280.130 habitantes. A pesar del crecimiento en el número de habitantes, la densidad de población sigue siendo relativamente baja, 9,7 habitantes por $\mathrm{km}^{2}$, cifra sustancialmente inferior a la observada en países de América Latina y el Caribe (ver Cuadro A.2 del apéndice).

Cuadro 1

Población Argentina según censos nacionales.

Años 1869-2001

\begin{tabular}{lccc}
\hline \hline Año & $\begin{array}{c}\text { Población } \\
\text { total }\end{array}$ & $\begin{array}{c}\text { Nro. } \\
\text { de años }\end{array}$ & $\begin{array}{c}\text { Tasa promedio anual } \\
\text { de crecimiento }\end{array}$ \\
\hline 1869 & $1,900,000$ & & \\
1895 & $4,044,911$ & 26 & 11.0 \\
1914 & $7,903,662$ & 19 & 36.0 \\
1947 & $15,893,827$ & 33 & 21.0 \\
1960 & $20,013,793$ & 13 & 18.0 \\
1970 & $23,364,431$ & 10 & 16.0 \\
1980 & $27,949,480$ & 10 & 18.0 \\
1991 & $32,615,528$ & 11 & 15.0 \\
2001 & $36,260,130$ & 11 & 10.1 \\
\hline
\end{tabular}

Fuente: Censos Nacionales de Población y Vivienda, INDEC.

En cuanto a la distribución de la población en el territorio, no ha sido, ni es en la actualidad homogénea. La dinámica demográfica de las provincias ha determinado la magnitud de su ocupación y su tendencia en el tiempo, definiendo perfiles demográficos y económicos. Un conjunto amplio de fuerzas socioeconómicas, tecnológicas, culturales y políticas, determinan el atractivo de las diversas áreas para su ocupación, y depende de su (i) grado de desarrollo y potencial económico, (ii) de aspectos educativos, (iii) de la calidad de vida que promete a sus habitantes, (iv) de la seguridad ciudadana, (v) condicionamientos y estabilidad política, (vi) factores socio-comunitarios ${ }^{6}$.

\footnotetext{
${ }^{6}$ En el Cuadro A.3 y Cuadro A.4 del Apéndice presenta la distribución de la población argentina por provincias según Censos Nacionales y Regiones geográficas.
} 
Estos factores han tenido importancia en nuestro país desde sus orígenes, si se observa que históricamente la población se concentraba en las provincias más ricas. Solo cinco provincias: Buenos Aires, Santa Fe, Córdoba, Entre Ríos y Tucumán, concentraban al 53\% de la población total en 1895. Desde entonces, se han observado cambios en la distribución de la población en nuestro territorio. El Cuadro 2 presenta un ranking de las provincias de acuerdo al porcentaje de la población total que en ellas reside según datos censales, ordenadas de acuerdo a su posición relativa respecto del primer censo nacional. Salvo en el caso de la provincia de Buenos Aires, que ha mantenido su liderazgo a lo largo de los años y las provincias de Santa Cruz y Tierra del Fuego que, aún experimentando crecimientos netos en el número de pobladores, continúan teniendo los porcentajes más bajos de población total del país, el resto de las provincias presentan una evolución algo dispar.

Cuadro 2

Ranking de provincias según porcentaje de la población total Censos Nacionales de 1895 a 2001

\begin{tabular}{|c|c|c|c|c|c|c|c|c|}
\hline Provincias & 1895 & 1914 & 1947 & 1960 & 1970 & 1980 & 1991 & 2001 \\
\hline Buenos Aires & 1 & 1 & 1 & 1 & 1 & 1 & 1 & 1 \\
\hline Resto de Buenos Aires & 2 & 2 & 3 & 3 & 3 & 3 & 3 & 3 \\
\hline Ciudad de Buenos Aires & 3 & 3 & 2 & 4 & 4 & 4 & 4 & 6 \\
\hline Santa Fe & 4 & 4 & 5 & 5 & 5 & 5 & 5 & 5 \\
\hline Córdoba & 5 & 5 & 6 & 6 & 6 & 6 & 6 & 4 \\
\hline Entre Ríos & 6 & 7 & 7 & 8 & 8 & 9 & 9 & 9 \\
\hline Corrientes & 7 & 8 & 10 & 11 & 11 & 12 & 12 & 13 \\
\hline Tucumán & 8 & 9 & 8 & 9 & 9 & 8 & 8 & 8 \\
\hline Santiago del Estero & 9 & 11 & 11 & 12 & 13 & 13 & 14 & 14 \\
\hline Salta & 10 & 12 & 13 & 13 & 12 & 11 & 10 & 10 \\
\hline 19 Partidos (2) & 11 & 6 & 4 & 2 & 2 & 2 & 2 & 2 \\
\hline Mendoza & 12 & 10 & 9 & 7 & 7 & 7 & 7 & 7 \\
\hline Catamarca & 13 & 16 & 19 & 20 & 21 & 23 & 22 & 22 \\
\hline San Juan & 14 & 13 & 14 & 15 & 15 & 15 & 15 & 15 \\
\hline San Luis & 15 & 14 & 18 & 19 & 20 & 21 & 21 & 21 \\
\hline La Rioja & 16 & 17 & 22 & 23 & 24 & 24 & 24 & 24 \\
\hline Jujuy & 17 & 18 & 17 & 16 & 16 & 16 & 16 & 16 \\
\hline Misiones & 18 & 19 & 15 & 14 & 14 & 14 & 13 & 12 \\
\hline La Pampa & 19 & 15 & 16 & 21 & 22 & 22 & 23 & 23 \\
\hline Neuquén & 20 & 22 & 24 & 24 & 23 & 20 & 19 & 19 \\
\hline Chaco & 21 & 20 & 12 & 10 & 10 & 10 & 11 & 11 \\
\hline Río Negro & 22 & 21 & 20 & 17 & 17 & 17 & 17 & 17 \\
\hline Formosa & 23 & 24 & 21 & 18 & 18 & 18 & 18 & 18 \\
\hline Chubut & 24 & 23 & 23 & 22 & 19 & 19 & 20 & 20 \\
\hline Santa Cruz & 25 & 25 & 25 & 25 & 25 & 25 & 25 & 25 \\
\hline Tierra del Fuego (3) & 26 & 26 & 26 & 26 & 26 & 26 & 26 & 26 \\
\hline
\end{tabular}

Nota: (2) Algunos componentes de estas dos jurisdicciones modificaron sus límites por lo cual los datos del 2001 no son estrictamente comparables con los de censos anteriores; (3) Para los censos de 1991 y 2001 se excluyen las Islas del Atlántico Sur; (4) En 1895 se estimaron 60.000 personas "sustraídas a la operación censal" y 30.000 indígenas; en 1914 se consignaron 18.425 habitantes como "población autóctona".

Fuente: Censos Nacionales de Población y Vivienda, INDEC

La provincia de Santa Fe ha perdido población respecto a otras provincias, junto con Catamarca, Corrientes, Entre Ríos, La Pampa, La Rioja, San Juan, San Luis y Santiago del Estero. Las provincias que han escalado posiciones en cuanto al porcentaje de la población total que vive en ellas son las provincias de Chaco, Chubut, Formosa, Jujuy, Mendoza, Misiones, Neuquén, Chaco, Río Negro ${ }^{7}$. Es notorio el caso de la Provincia de Buenos Aires, cuando se consideran de manera separada la evolución de la población localizada en la ciudad de Buenos Aires, en los 19 partidos que integran el conurbano bonaerense o el resto de la provincia de Buenos Aires. En el caso de la primera, ésta ha perdido posiciones en el ranking. Mientras que en 1895 era la tercera localidad con mayor proporción de habitantes, en la actualidad es la sexta. El resto de la provincia de

${ }^{7}$ Es importante notar, que en algunos casos, el crecimiento población responde o solo a los movimientos internos de la población, sino a las mayores tasas de natalidad y crecimiento de la población en estas provincias. 
Buenos Aires, en cambio, si bien ha perdido población, se ha mantenido como la tercera región con mayor población de nuestro país. Contrariamente, los 19 partidos que integran el Gran Buenos Aires que era la undécima localidad con mayor porcentaje de población en 1895, en la actualidad es la segunda área más poblada de nuestro país. Esto no resulta extraño si se tiene en cuenta que desde las últimas décadas se observa un constante movimiento de la población hacia fuera de la Capital Federal. Las provincias de Salta y Tucumán, si bien tienen períodos con mayor población, en general han mantenido su posición, siendo en la actualidad la décima y octava provincia, respectivamente, con mayor población en nuestro país.

\subsection{Composición población según su origen: población nativa y extranjera}

De acuerdo a los dos primeros censos la población nativa era aproximadamente el $83 \%$ de la población total, porcentaje que disminuye considerablemente hacia 1914, con la llegada de los inmigrantes europeos. En la actualidad el $95 \%$ de la población total de nuestro país es nativa y solo el $5 \%$ es extranjera.

Existen numerosos registros que dan cuenta del gran flujo de inmigrantes extranjeros ocurrido a partir de 1846, su origen y su distribución espacial, principalmente en Capital Federal, Buenos Aires, Santa Fe, Entre Ríos y Corrientes que absorbieron más del $80 \%$ de la población extranjera censada en toda la Argentina ${ }^{8}$, por entonces, la migración de extranjeros era el principal factor de crecimiento y explicaba la dinámica de la población del país.

El Gráfico 2 se sintetiza la composición de la población argentina, según lugar de nacimiento. Como se observa, en los primeros períodos censales hay un importante crecimiento del porcentaje de población extranjera, producto de las migraciones internacionales.

Gráfico 2

Composición de la población según lugar de nacimiento.

Total del país. Años 1869-2001.

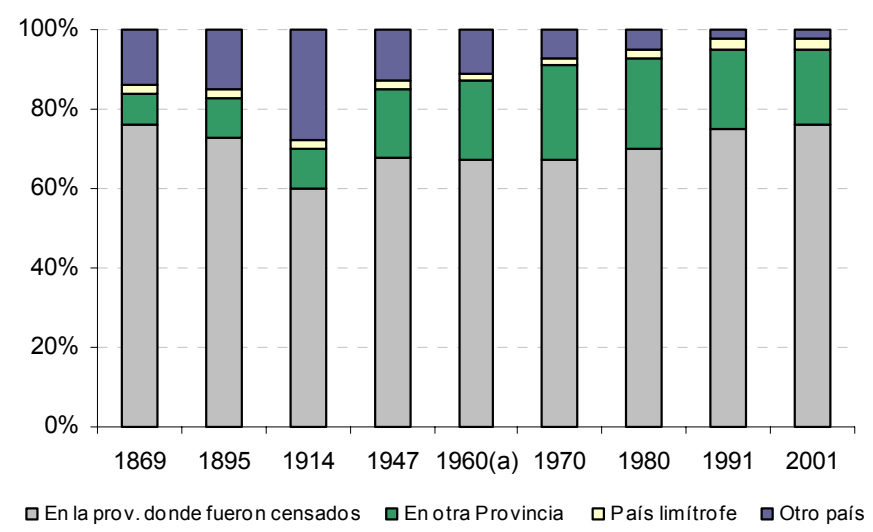

Fuente: Censos Nacionales de Población y Vivienda, INDEC.

Pero a diferencia de los registros (más detallados) sobre el ingreso de extranjeros al país, solo para algunas provincias o ciudades es posible encontrar información sobre movimientos internos de la población nativa. El censo de 1869 es la primera fuente de información sobre migraciones internas de alcance nacional, que por entonces apenas alcanzaban al 8,3\% del total de la población y perdía relevancia frente a los migrantes extranjeros que representaban el $15 \%$ de la población total.

8 En estas provincias se acento el $91 \%$ de los inmigrantes según el censo de 1869 , el 87,8\% según datos de 1895 y el $80,4 \%$ en 1914. 
Con la considerable disminución del volumen de migrantes internacionales, la migración de la población nativa, que había permanecido estable, aumenta fuertemente y se convierte, hasta la actualidad, en el factor dominante dentro del fenómeno migratorio. Como se observa en el Cuadro 3, según datos del Censo 2001, los migrantes internacionales representan apenas el 5\% del total de la población ${ }^{9}$, mientras que el $19 \%$ de la población nativa ha migrado internamente (vive en una provincia distinta a la de su nacimiento). Las migraciones internas fueron aun más importantes en años anteriores. Según los datos del censo 1970/1980, alrededor del 24\% de la población nativa había migrado a otra provincia o localidad.

Cuadro 3

Origen de la población nativa y no nativa según censos nacionales. Total del país. Años 1914-1991. En Porcentajes

\begin{tabular}{lcccccccc}
\hline \hline & & \multicolumn{3}{c}{ Nacidos en el país } & & \multicolumn{3}{c}{ Nacidos en el exterior } \\
\cline { 3 - 5 } Censo & Total & Total & $\begin{array}{c}\text { En la provincia } \\
\text { donde fueron } \\
\text { censados }\end{array}$ & $\begin{array}{c}\text { En otra } \\
\text { Provincia }\end{array}$ & & Total & $\begin{array}{c}\text { País } \\
\text { limítrofe }\end{array}$ & $\begin{array}{c}\text { Otro } \\
\text { país }\end{array}$ \\
\hline 1869 & 100 & 84 & 76 & 8 & 16 & 2 & 14 \\
1895 & 100 & 83 & 73 & 10 & & 17 & 2 & 15 \\
1914 & 100 & 70 & 60 & 10 & & 30 & 2 & 28 \\
1947 & 100 & 85 & 68 & 17 & & 15 & 2 & 13 \\
1960 & 100 & 87 & - & - & & 13 & 2 & 11 \\
1970 & 100 & 91 & 67 & 24 & & 9 & 2 & 7 \\
1980 & 100 & 93 & 70 & 23 & & 7 & 2 & 5 \\
1991 & 100 & 95 & 75 & 20 & & 5 & 3 & 2 \\
2001 & 100 & 95 & 76 & 19 & & 5 & 3 & 2 \\
\hline
\end{tabular}

Nota: El Censo de 1960 no distinguía entre nacidos en la jurisdicción y en el resto del país. Fuente: Censos Nacionales de Población y Vivienda, INDEC.

Teniendo en cuenta que las migraciones internas, explican en los últimos años el movimiento de personas en nuestro país, resulta obvia la importancia de estudiar este fenómeno en nuestro país, y que por otra parte, se encuentra en sintonía con lo observado a nivel internacional.

\section{Migraciones internas en Argentina}

Las migraciones internas se definen como el cambio de residencia de una persona dentro de un país, implicando esto el cruce de un límite político-administrativo oficial (Macció (1985)). Como se mostró en el Cuadro 3, en Argentina, este fenómeno ha adquirido una importante magnitud en las últimas décadas.

En el Cuadro 5 se presentan los movimientos inter-provinciales de la poblacion nativa según datos del Censo 2001. La columna (I) incluye la población por provincias, mientras que en la columna (II) y (III) se reporta el número total de inmigrantes y emigrantes internos por provincias. El saldo neto de estas corrientes contrapuestas corresponde a la migración interna neta por provincias (columna IV). Como se observa, varias provincias, entre ellas Córdoba, Entre Ríos, Formosa, Jujuy y Misiones tienen saldos negativos indicando una perdida neta de población.

Las tasas de inmigración y emigración ${ }^{10}$, se estiman en las columnas (V) y (VI). Entre las provincias con mayores tasas de inmigración se encuentran las provincias de Tierra del Fuego

\footnotetext{
${ }^{9}$ En su mayoría proveniente de países limítrofes: Bolivia, Uruguay y Paraguay

$10 \mathrm{La}$ tasa de inmigración a la provincia (j) se calcula como inmigrantes del período (Ij ) sobre población de la localidad de destino (j) en el período. La tasa de emigración sigue la misma lógica y sólo cambia porque incluye a los emigrantes en el numerador. La tasa de migración neta se obtiene como diferencia de la tasa de inmigración y emigración. Su signo puede ser positivo o negativo y se interpreta como el cambio relativo en la cuantía de la población como resultado del balance entre inmigrantes y emigrantes (para mayor detalle ver Rodríguez (2004)).
} 
(13.69\%), Santa Cruz (9.95\%), San Luis (6.95\%), Corrientes (6.11\%), Neuquén (6.09\%) y la Rioja (6.07\%). También resulta notoria la tasa de inmigración de Capital Federal (7.20\%) cuando se desagrega la información disponible para la provincia de Buenos Aires.

Cuadro 5

Migraciones internas en argentina

Tasas de inmigración y emigración por provincia

\begin{tabular}{|c|c|c|c|c|c|c|c|}
\hline \multirow{3}{*}{ Provincia } & \multirow{3}{*}{$\frac{\text { Población }^{(*)}}{(\mathrm{I})}$} & \multicolumn{2}{|c|}{ Número de } & \multirow{3}{*}{$\begin{array}{c}\begin{array}{c}\text { Migración } \\
\text { interna neta }\end{array} \\
\text { (IV) }\end{array}$} & \multicolumn{2}{|c|}{ Tasa Bruta de } & \multirow{3}{*}{$\begin{array}{c}\begin{array}{c}\text { Tasa Neta de } \\
\text { Migración }\end{array} \\
(\mathrm{VII})\end{array}$} \\
\hline & & Inmigrantes & Emigrantes & & Inmigración & Emigración & \\
\hline & & (II) & (III) & & $(\mathrm{V})$ & $(\mathrm{VI})$ & \\
\hline Capital Federal & $2,670,449$ & 192,275 & 252,512 & $-60,237$ & 7.20 & 9.46 & -2.26 \\
\hline Buenos Aires & $12,579,335$ & 329,931 & 275,865 & 54,066 & 2.62 & 2.19 & 0.43 \\
\hline Catamarca & 295,369 & 11,634 & 8,238 & 3,396 & 3.94 & 2.79 & 1.15 \\
\hline Chaco & $2,790,514$ & 84,648 & 64,276 & 20,372 & 3.03 & 2.30 & 0.73 \\
\hline Chubut & 823,990 & 27,649 & 34,303 & $-6,654$ & 3.36 & 4.16 & -0.81 \\
\hline Cordoba & 869,129 & 20,595 & 32,137 & $-11,542$ & 2.37 & 3.70 & -1.33 \\
\hline Corrientes & 370,928 & 22,654 & 19,868 & 2,786 & 6.11 & 5.36 & 0.75 \\
\hline Entre Rios & $1,040,387$ & 31,578 & 34,379 & $-2,801$ & 3.04 & 3.30 & -0.27 \\
\hline Formosa & 426,584 & 9,874 & 14,689 & $-4,815$ & 2.31 & 3.44 & -1.13 \\
\hline Jujuy & 542,353 & 17,545 & 23,216 & $-5,671$ & 3.23 & 4.28 & -1.05 \\
\hline La Pampa & 272,903 & 13,218 & 11,763 & 1,455 & 4.84 & 4.31 & 0.53 \\
\hline La Rioja & 259,142 & 15,737 & 5,742 & 9,995 & 6.07 & 2.22 & 3.86 \\
\hline Mendoza & $1,431,637$ & 31,954 & 35,006 & $-3,052$ & 2.23 & 2.45 & -0.21 \\
\hline Misiones & 841,983 & 23,662 & 31,160 & $-7,498$ & 2.81 & 3.70 & -0.89 \\
\hline Neuquen & 425,431 & 25,922 & 20,919 & 5,003 & 6.09 & 4.92 & 1.18 \\
\hline Rio Negro & 497,222 & 25,494 & 30,662 & $-5,168$ & 5.13 & 6.17 & -1.04 \\
\hline Salta & 946,381 & 27,858 & 32,144 & $-4,286$ & 2.94 & 3.40 & -0.45 \\
\hline San Juan & 554,367 & 13,601 & 12,728 & 873 & 2.45 & 2.30 & 0.16 \\
\hline San Luis & 328,095 & 22,816 & 12,303 & 10,513 & 6.95 & 3.75 & 3.20 \\
\hline Santa Cruz & 175,624 & 17,482 & 12,788 & 4,694 & 9.95 & 7.28 & 2.67 \\
\hline Santa Fe & $2,753,616$ & 54,444 & 52,446 & 1,998 & 1.98 & 1.90 & 0.07 \\
\hline Santiago del Estero & 706,273 & 18,883 & 23,817 & $-4,934$ & 2.67 & 3.37 & -0.70 \\
\hline Tierra Fuego & 90,086 & 12,332 & 9,210 & 3,122 & 13.69 & 10.22 & 3.47 \\
\hline Tucuman & $1,193,409$ & 25,050 & 26,665 & $-1,615$ & 2.10 & 2.23 & -0.14 \\
\hline Total & $32,885,207$ & $1,076,836$ & $1,076,836$ & & 4.46 & 4.13 & \\
\hline
\end{tabular}

$\left(^{*}\right)$ Corresponde a personas que declararon no residir en la misma jurisdicción (migrantes interprovinciales). No se tiene en cuenta a las personas que no reportaron el lugar de residencia anterior o a las que no se conoce la provincia de origen, como así tampoco las personas que vivían en el período de referencia en el exterior o que al momento del Censo abandonaron el país.

Fuente: Estimación propia en base al Censo Nacional de Población y Vivienda 2001, INDEC.

No sorpresivamente las provincias con mayor tasas de emigración son también Tierra del Fuego (10.2\%), Capital Federal (9.46\%) Santa Cruz (7.28\%) y Río Negro (6.17\%), Corrientes (5.36\%) y Neuquén (4.92\%), lo cual indica que los mayores intercambios poblacionales se dan entre las provincias menos pobladas (las provincias de la región patagónica). De acuerdo con Plane y Rogerson (1994) es común encontrar áreas deprimidas con tasas de emigración superiores a las tasas de inmigración (emigración neta) y niveles bajos de movimientos. Pero esto no ocurre en Argentina.

Las provincias con bajo nivel de movimiento poblacional, con tasas de netas de migración cercanas a cero, son las provincias de Córdoba, Formosa, Mendoza, San Juan y Santa Fe. Las provincias más pobres como Chaco, Corrientes, tienen tasas netas de migración positivas, con lo cual han ganado población.

En el Gráfico 3 se representan las tasas de emigración e inmigración interprovincial ${ }^{11 .}$ Las provincias que se encuentran por encima de la diagonal, presentan tasas de emigración superiores a las tasas de inmigración. En estas provincias la tasa neta de migración es negativa dado que expulsan más población de la que reciben. Pertenecen a este grupo, las provincias de Córdoba,

${ }^{11}$ La línea de 45grados, que divide el gráfico indica la igualdad entre las tasas de emigración e inmigración. 
Formosa, Jujuy, Río Negro, Misiones, Chubut, Santiago del Estero, Salta y Entre Ríos. Contrariamente las provincias ubicadas debajo de la diagonal tienen tasas de inmigración superiores a las tasas de emigración, de modo tal que el flujo migratorio neto resulta positivo. Entre estas provincias se encuentran las provincias patagónicas (Santa Cruz, Tierra del Fuego, Chubut, Neuquén), las provincias con fuertes regimenes de promoción industrial, como San Luis, Catamarca y La Rioja, la provincia de Buenos Aires y Córdoba. En el caso de las provincias de Santa Fe, Tucumán, Mendoza, San Juan y Entre Ríos, las tasas de inmigración y emigración resultan muy similares, presentando tasas de migración neta cercanas a cero. Es importante notar que son las provincias menos pobladas y más alejadas del centro del país, Tierra del Fuego, Santa Cruz, Neuquén y Río Negro, las que presentan las mayores tasas de inmigración y emigración, indicando gran movimiento poblacional en estas provincias.

Gráfico 3

Tasas de emigración e inmigración interprovincial

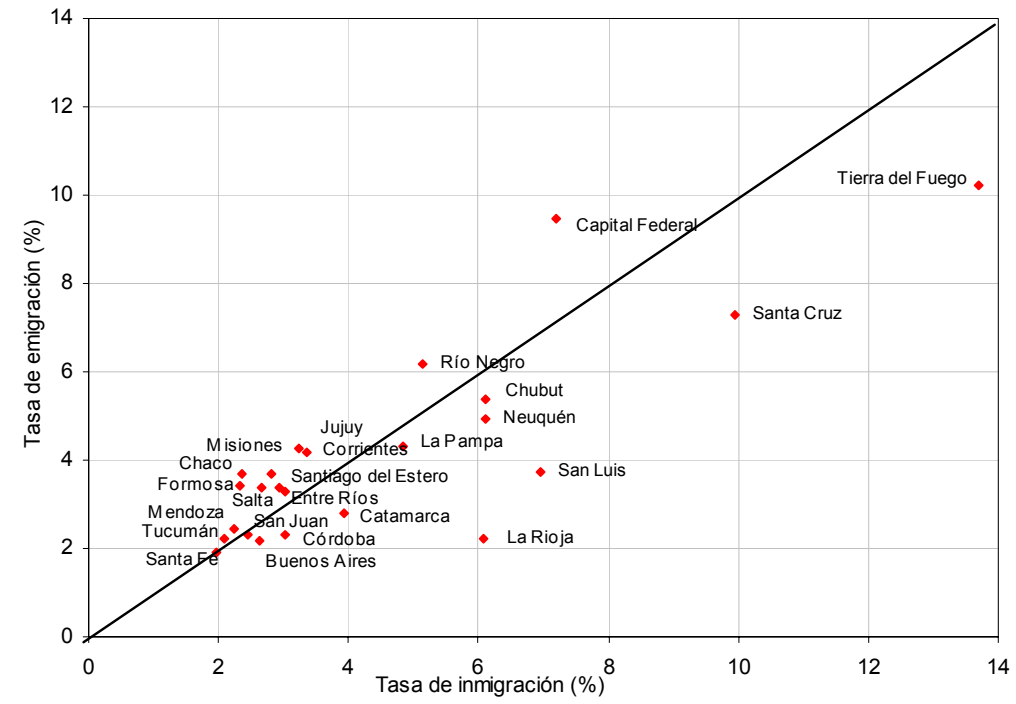

Fuente: Estimación propia en base al Censo Nacional de Población y Vivienda 2001, INDEC.

Por regiones geográficas (Cuadro 6), se observa el mismo patrón, donde la región Patagónica presenta tasa neta de inmigración positiva, junto con la región Pampeana y Cuyo. Contrariamente, las regiones del NOA Y NEA tienen saldos migratorios negativos. Se destaca principalmente la región nordeste con una tasa de migración neta de -1.03.

Cuadro 6

Migraciones internas en argentina

Tasas de inmigración y emigración por regiones

\begin{tabular}{|c|c|c|c|c|c|c|c|c|}
\hline \multirow[b]{2}{*}{ Provincia/ Región } & \multirow{2}{*}{$\begin{array}{c}\text { Población } \\
\text { Total }\end{array}$} & \multirow{2}{*}{$\begin{array}{l}\text { Población } \\
\text { disponible }\end{array}$} & \multicolumn{2}{|c|}{ Número de } & \multirow{2}{*}{$\begin{array}{c}\text { Migración } \\
\text { interna neta }\end{array}$} & \multicolumn{2}{|c|}{ Tasa Bruta de } & \multirow{2}{*}{$\begin{array}{c}\text { Tasa Neta de } \\
\text { Migración }\end{array}$} \\
\hline & & & Inmigrantes & $\overline{\text { Emigrantes }}$ & & Inmigración & Emigración & \\
\hline Buenos Aires & $16,603,341$ & $15,113,026$ & 205,435 & 211,606 & $-6,171$ & 1.36 & 1.40 & -0.04 \\
\hline Pampeana & $7,524,943$ & $6,838,513$ & 139,252 & 118,228 & 21,024 & 2.04 & 1.73 & 0.31 \\
\hline Cuyo & $2,567,607$ & $2,304,278$ & 52,377 & 44,043 & 8,334 & 2.27 & 1.91 & 0.36 \\
\hline Nordeste & $3,367,518$ & $2,952,125$ & 58,738 & 89,247 & $-30,509$ & 1.99 & 3.02 & -1.03 \\
\hline Noroeste & $4,458,470$ & $3,929,106$ & 78,451 & 81,566 & $-3,115$ & 2.00 & 2.08 & -0.08 \\
\hline Patagonia & $1,738,251$ & $1,550,950$ & 72,537 & 62,100 & 10,437 & 4.68 & 4.00 & 0.67 \\
\hline Total & $36,260,130$ & $32,687,998$ & 606,790 & 606,790 & & 2.39 & 2.36 & \\
\hline
\end{tabular}

Fuente: Estimación propia en base al Censo Nacional de Población y Vivienda 2001, INDEC. 
En el Grafico 4 se presentan estos resultados por regiones. Es importante notar que en el caso de la provincia de Buenos Aires, la tasa de emigración es muy similar a la tasa de inmigración, pero como se observó en el gráfico anterior (Gráfico 3), los resultados para esta provincia son muy distintos cuando se considera en forma separada Capital Federal y el resto de la provincia de Buenos Aires.

\section{Gráfico 4}

Tasas de emigración e inmigración entre regiones geográficas

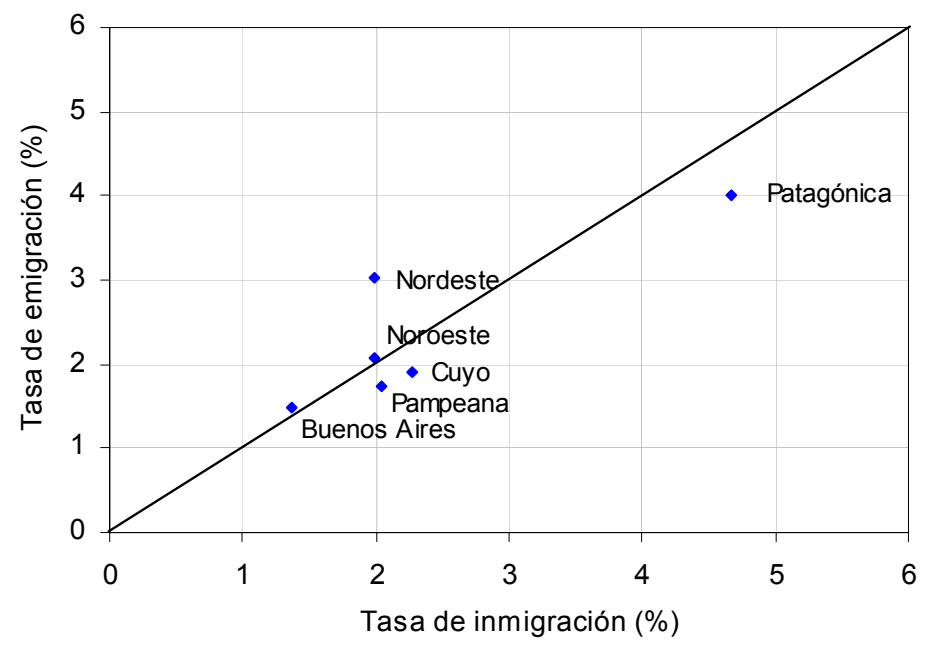

Fuente: Estimación propia en base al Censo Nacional de Población y Vivienda 2001, INDEC.

\section{CARACTERÍSTICAS SOCIODEMOGRÁFICAS DE LA POBLACIÓN MIGRANTE}

No toda la población participa del fenómeno migratorio. Una extensa literatura da cuenta de la existencia de selectividad en las migraciones en términos de ciertas características sociodemográficas ${ }^{12}$. Con tal motivo se describen a continuación, algunas características de la población migrante y no migrante, a partir de microdatos provenientes de la Encuestas Permanente de Hogares de Mayo de $2003^{13}$.

El Cuadro 7 muestra la población total argentina, según su condición de migración. A mayo de 2003, cerca de 4 millones de personas han migrado internamente, es decir, el $16.3 \%$ de la población argentina. El 84.6\% de los migrantes internos han llegado al lugar de destino hace mas de 6 años y una menor proporción (15.4\%) corresponde a migrantes recientes.

Cuadro 7

Población total según condición de migración

Total de aglomerados urbanos, mayo 2003.

\begin{tabular}{lrc}
\hline \hline \multicolumn{1}{c}{ Condición de migración } & \multicolumn{1}{c}{ Total } & Porcentaje \\
\hline Población total & $24,493,381$ & 100.0 \\
No migrantes & $20,509,857$ & 83.7 \\
Migrantes internos & $3,983,524$ & 16.3 \\
Migrantes de los últimos 5 años & 612,728 & 15.4 \\
Migrantes de más de 5 años & $3,370,796$ & 84.6 \\
\hline
\end{tabular}

Fuente: Estimación propia en base a la Encuesta Permanente de Hogares (EPH), INDEC.

\footnotetext{
${ }^{12}$ Ver Borjas (1996)

${ }^{13}$ Es importante aclarar que la totalidad de los valores de los cuadros que se incluyen se refieren al período de llegada al área de los que la EPH encuentra en la presente onda de relevamiento. No incluye, por tanto, a aquellos que habiendo llegado en esos períodos emigraron del área o fallecieron con anterioridad a esta onda, y por lo tanto no refleja perfectamente la evolución del proceso migratorio en el tiempo.
} 
Como veremos en los cuadros siguientes, existen importantes diferencias entre los migrantes internos que han cambiado su lugar de residencia en los últimos 5 años, es decir, los migrantes recientes, respecto de la población nativa e inclusive, de las personas que habiendo migrado, tienen mas de 6 años de residencia en el lugar de destino. Como se demostrará en los cuadros siguientes, estas personas que se encuentran establecidas por periodo mayor de tiempo en las localidades a las que migraron, comparten características socio-económicas similares a la de la población nativa.

\subsection{Género y edad}

En el Cuadro 8 muestra la población por condición de migración según sexo. Como puede observarse el porcentaje de mujeres en la población total es superior a los hombres. Este mismo patrón se observa tanto en la población no migrante y los migrantes internos. Entre los migrantes internos, el 53\% son mujeres, mientras que el $47 \%$ son hombres. Esta mayor predisposición femenina a migrar es una característica histórica de los movimientos internos en argentina y de los países de América Latina (Rodríguez (2002); Chant (1999); Szasz (1995)). Estos autores lo atribuyen principalmente a la importancia del flujo rural-urbano y a los espacios laborales específicos que tienen las mujeres migrantes en las ciudades, como el sector servicios o el empleo doméstico. Bilsborrrow (1987) también coincide con estos resultados, afirmando que las mujeres migrantes son en promedio más jóvenes, aunque también menos educadas y con una mayor probabilidad de ser solteras que los migrantes hombres.

Cuadro 8

Población total por condición de migración según sexo. Total de aglomerados urbanos, Onda Mayo 2003.

\begin{tabular}{|c|c|c|c|c|c|}
\hline \multirow{2}{*}{ Condición de migración } & \multirow{2}{*}{ Total } & \multicolumn{2}{|c|}{ Mujeres } & \multicolumn{2}{|c|}{ Hombres } \\
\hline & & Total & Porcentaje & Total & Porcentaje \\
\hline Población total & $24,493,381$ & $12,844,964$ & 52.4 & $11,648,417$ & 47.6 \\
\hline No migrantes & $20,509,857$ & $10,748,636$ & 52.4 & $9,761,221$ & 47.6 \\
\hline Migrantes internos & $3,983,524$ & $2,096,328$ & 52.6 & $1,887,196$ & 47.4 \\
\hline Migrantes de los últimos 5 años & 612,728 & 310,298 & 50.6 & 302,430 & 49.4 \\
\hline Migrantes de más de 5 años & $3,370,796$ & 1786030 & 53.0 & 1584766 & 47.0 \\
\hline
\end{tabular}

Fuente: Estimación propia en base a la Encuesta Permanente de Hogares (EPH), INDEC.

El predominio de las mujeres dentro de los migrantes internos persiste aún cuando se consideran distintos grupos etáreos. En el Cuadro 9 se presentan la composición por sexo de la población migrante y no migrante según grupos de edad. Como se observa, salvo en el grupo de entre 0 y 14 años, el porcentaje de mujeres que migran es mayor, hecho que se acentúa en los grupos de edad mas avanzadas debido a la mayor expectativa de vida de las mujeres en relación a los hombres.

Cuadro 9

Población total por condición de migración según grupos de edad y género. Total de aglomerados urbanos, Onda Mayo 2003.

\begin{tabular}{|c|c|c|c|c|c|c|c|c|c|c|}
\hline \multirow{3}{*}{ Condición de migración } & \multicolumn{9}{|c|}{ Grupo de edad } & \\
\hline & \multirow{2}{*}{\multicolumn{2}{|c|}{$\frac{0-14 \text { años }}{\text { Mujeres Hombres }}$}} & \multirow{2}{*}{\multicolumn{2}{|c|}{$\frac{15-24 \text { años }}{\text { Mujeres Hombres }}$}} & \multirow{2}{*}{\multicolumn{2}{|c|}{$\frac{25-40 \text { años }}{\text { Mujeres Hombres }}$}} & \multirow{2}{*}{\multicolumn{2}{|c|}{$\frac{41-64 \text { años }}{\text { Mujeres Hombres }}$}} & \multirow{2}{*}{\multicolumn{2}{|c|}{$\begin{array}{c}65 \text { años y más } \\
\text { Mujeres Hombres }\end{array}$}} \\
\hline & & & & & & & & & & \\
\hline Población total & 49.1 & 50.9 & 51.3 & 48.7 & 53.1 & 46.9 & 52.8 & 47.2 & 61.3 & 38.7 \\
\hline No migrantes & 49.3 & 50.8 & 51.4 & 48.6 & 53.1 & 46.9 & 53.2 & 46.8 & 62.1 & 37.9 \\
\hline Migrantes internos & 44.5 & 55.5 & 50.6 & 49.4 & 52.9 & 47.2 & 51.7 & 48.3 & 58.9 & 41.1 \\
\hline Migran & 41.8 & 58.2 & 55.4 & 44.6 & 53.3 & 46.7 & 39.5 & 60.5 & 77.6 & 22.4 \\
\hline Migrantes de más de 5 años & 48.0 & 52.1 & 47.0 & 53.0 & 52.7 & 47.3 & 52.4 & 47.7 & 58.4 & 41.6 \\
\hline
\end{tabular}

Fuente: Estimación propia en base a la Encuesta Permanente de Hogares (EPH), INDEC. 
La edad promedio en la que los individuos toman su decisión de migración es a los 20 años en el caso de las mujeres, y 19 años en el caso de los hombres. Como se observa en el Gráfico 5, el porcentaje de migrantes en relación a su edad presenta una leve forma de $\mathrm{U}$ en la etapa inicial con un alto porcentaje de niños menores de 3 años (que migran como consecuencia de las decisiones de migración de sus padres) y decrece a medida que los niños comienzan su etapa escolar (primaria y secundaria). La mayor frecuencia migratoria ocurre al inicio de la vida activa de las personas, es decir, entre los 20 y 26 años. Es en esta etapa cuando se adoptan decisiones asociadas a cambio de residencia, como el ingreso a la universidad o a la incorporación al mercado de trabajo, la formación de una familia, etc.

La probabilidad de migrar, como se observa en el gráfico tiende a decrecer con la edad de las personas. Según la hipótesis que estudia a las migraciones como una inversión en capital humano, es lógico que estas decaigan con la edad de los individuos. A medida que una persona se vuelve mayor hay un período más corto de tiempo en el cual puede materializar las ganancias netas derivadas de su decisión de migrar. Si bien para muchos países se observa un aumento en las migraciones de personas edad de retiro, es decir personas de más de 60 años que dejan de participar en el mercado laboral, no se observa en nuestro país este fenómeno.

Gráfico 5

Edad al momento migrar

Total de aglomerados urbanos.

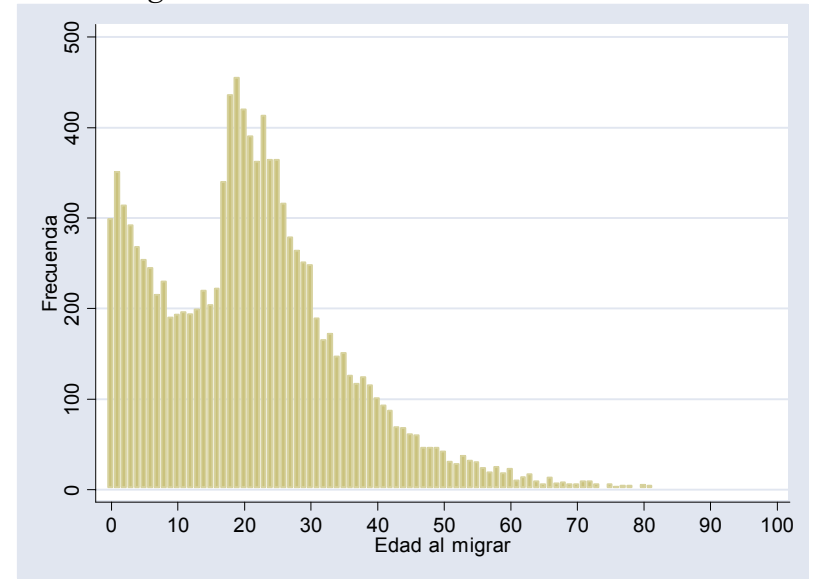

Fuente: Estimación propia en base a la Encuesta Permanente de Hogares (EPH), INDEC.

\subsection{Estado Civil}

En cuanto al estado civil de los migrantes, se observa que a excepción de las personas que migraron en los últimos 5 años, el porcentaje de migrantes casado o en unión civil es superior al de la población no migrante. En general, las decisiones de migración se analizan desde el punto de vista del individuo, pero una distinción cada vez más común en la literatura es considerar que las decisiones de migración son tomadas por las unidades familiares ${ }^{14}$. Para evaluar si las decisiones de migración interna en nuestro país fueron tomadas por individuos solteros o principalmente por personas casadas, con un hogar ya conformado, se aproximó el estado civil de las personas al momento de migrar, considerando el año de migración, que ambos esposos sean migrantes, tengan el mismo lugar o provincia de origen y la edad del mayor de los hijos. Los

\footnotetext{
${ }^{14}$ En estos casos, la decisión de migrar no se basa en un modelo de maximización de utilidad de un individuo, sino de la maximización conjunta de utilidades de los miembros del hogar.
} 
resultados, si bien aproximados, indican que $65 \%$ de los migrantes internos migró ya casado. El porcentaje es menor para los migrantes recientes, entre los cuales hay un mayor predominio de personas aun solteras.

Cuadro 10

Población de 18 años o más, según condición de migración y estado civil.

Total de aglomerados urbanos, Onda Mayo 2003.

\begin{tabular}{lcccc}
\hline \hline & \multicolumn{4}{c}{ Estado Civil } \\
\cline { 2 - 5 } & Soltero & Casado o unido Separado & Viudo \\
\hline Población total & 39.7 & 52.3 & 5.7 & 2.3 \\
No migrantes & 43.5 & 49.2 & 5.5 & 1.9 \\
Migrantes internos & 24.3 & 65.3 & 6.6 & 3.9 \\
$\quad$ Migrantes de los últimos 5 años & 48.8 & 46.6 & 3.0 & 1.6 \\
Migrantes de más de 5 años & 19.9 & 68.6 & 7.2 & 4.3 \\
\hline
\end{tabular}

Fuente: Estimación propia en base a la Encuesta Permanente de Hogares (EPH), INDEC.

\subsection{Composición y características de los hogares}

En cuanto a las características de los hogares que conforman las personas migrantes o no migrantes. Como se puede observa en el Cuadro 12, los hogares que han migrado recientemente, en los últimos 5 años, presentan una composición y características socio-demográficas distintas a las observadas para la población no migrante o los migrantes de más de 6 años.

Cuadro 12

Población total según condición de migración y caracteristicas de los hogares

Total de aglomerados urbanos, Onda Mayo 2003.

\begin{tabular}{|c|c|c|c|c|c|}
\hline \multirow{3}{*}{ Caracteristicas del hogar } & \multicolumn{5}{|c|}{ Condición de migración } \\
\hline & \multirow[b]{2}{*}{$\begin{array}{c}\text { No } \\
\text { Migrante }\end{array}$} & & \multicolumn{3}{|c|}{ Migrantes internos } \\
\hline & & & Total & $\begin{array}{l}\text { Migrante } \\
\text { Reciente }\end{array}$ & $\begin{array}{l}\text { Migrantes de } \\
\text { más de } 5 \text { años }\end{array}$ \\
\hline Tipo de hogar & & & & & \\
\hline Hogar completo & 28.99 & & 33.41 & 32.19 & 34.35 \\
\hline Numero de miembros del hogar & & & & & \\
\hline Número de miembros & 3.36 & & 3.54 & 2.76 & 3.62 \\
\hline Número de hijos menores de 6 años & 0.35 & & 0.32 & 0.37 & 0.32 \\
\hline Numero de hijos de entre 6 y 18 años & 0.72 & & 0.83 & 0.52 & 0.86 \\
\hline Sexo del Jefe de hogar & & & & & \\
\hline Hombre & 69.66 & & 70.92 & 70.51 & 70.97 \\
\hline Nivel educativo del jefe de hogar & & & & & \\
\hline Bajo & 41.81 & & 55.68 & 23.08 & 59.04 \\
\hline Medio & 36.05 & & 26.65 & 32.40 & 26.06 \\
\hline Alto & 22.14 & & 17.67 & 44.52 & 14.91 \\
\hline Estado ocupacional del jefe de hogar & & & & & \\
\hline Ocupado & 64.54 & \# & 60.22 & 60.92 & 60.15 \\
\hline Desocupado & 7.47 & \# & 9.56 & 11.00 & 9.00 \\
\hline Niños del hogar que trabajan & 0.236 & & 2.057 & 4.990 & 0.242 \\
\hline Perceptores de ingresos & & & & & \\
\hline Personas del hogar que reciben ingreso & 55.33 & & 53.37 & 56.10 & 53.08 \\
\hline
\end{tabular}

Fuente: Estimación propia en base a la Encuesta Permanente de Hogares (EPH), INDEC.

El número promedio de personas por hogar de los hogares que han migrado recientemente es menor a 3 miembros por hogar. Mientras que en el caso de los no migrantes o de los hogares que se migraron hace más de 5 años el número de miembros por hogar es cercano a 4 personas. El 
número de niños menores de 6 años es mayor en los hogares que han migrado en los últimos 5 años, mientras que en los hogares que migraron hace varios años atrás, hay un predominio de hijos mayores de 6 años de edad. Estos hechos tienen sentido, si se tiene en cuenta el impacto sobre la decisión de migración que tiene la presencia de niños en edad escolar.

El porcentaje de hogares en que ambos cónyuges están presentes (hogares completos), es menor para los migrantes recientes (32\%) en comparación con quienes han migrado antes de 1998, es decir, hace mas de 5 años (35\%), pero ambos son mayores que el porcentaje de hogares completos observado para los no migrantes (29\%). El porcentaje de jefes de hogar hombres es similar para ambas poblaciones (el 70\% de los jefes de hogar, sean migrantes o no, son hombres). Si se observan importantes diferencias en los niveles educativos del jefe de hogar. Un menor porcentaje de jefes de hogar entre los migrantes reciente tiene nivel educativo bajo (23\%), respecto al total de migrantes internos (59\%). El trabajo infantil es superior en los hogares que han migrado recientemente. Como consecuencia, también es superior el número de perceptores de ingresos de esos hogares.

\subsection{Características educacionales de la población migrante}

Durante la migración masiva hacia las ciudades durante el éxodo rural, la población migrante presentaba bajo nivel de educación o alfabetismo (Elizaga y Marisco (1975). Simmons (1978)), , pero según la evidencia para otros países, en la actualidad, se observa que los migrantes internos tienen, en promedio mayor años de educación que la población nativa. Esta correlación se debe, como argumentan Islam y Choudhury (1990) y Borjas (2000) que los individuos más educados son más eficientes en aprender, adaptarse y obtener información acerca de posibilidades de empleo en mercados alternativos, lo cual reduce los costos de migrar.

En nuestro país, no se observa esta tendencia. Como se muestra en el Cuadro 13, los años promedio de educación de la población de 25 a 55 años de edad, es menor para los migrantes internos (con un promedio 9 años de educación) que para los no migrantes (con 11 años de educación). Si en cambio se verifican las tendencias internacionales entre quienes han migrado recientemente, para este grupo, el promedio de años de educación es de 11 años. Según género, se observa que entre los migrantes, las mujeres tienen menos años de educación que los hombres.

Cuadro 13

Población total según condición de migración y años de educación Total de aglomerados urbanos, Onda Mayo 2003.

\begin{tabular}{lcccc}
\hline \hline & \multicolumn{3}{c}{ Años de educación (promedio) } \\
\cline { 2 - 5 } & $\begin{array}{c}\text { Población } \\
\text { total }\end{array}$ & \multicolumn{3}{c}{ Población de 25 a 65 años } \\
\cline { 2 - 5 } & 8.2 & 10.4 & 10.2 & 10.3 \\
\hline Población total & 8.1 & 10.8 & 10.5 & 10.7 \\
No migrantes & 8.9 & 9.2 & 9.3 & 9.2 \\
Migrantes internos & 9.7 & 10.9 & 11.2 & 11.0 \\
Migrantes de los últimos 5 años & 8.7 & 9.0 & 9.1 & 9.0 \\
Migrantes de más de 5 años & &
\end{tabular}

Fuente: Estimación propia en base a la Encuesta Permanente de Hogares (EPH), INDEC.

Según zonas geográficas hay importantes diferencias en los años de educación de la población migrante y no migrante (Gráfico 6). En los aglomerados de la región Patagónica, NOA, NEA y Cuyo, los migrantes internos tienen en promedio mayor años de educación que la población nativa, para todos los grupos de edad. En el caso de los migrantes internos de la región Patagónica, estos tienen en promedio 2 años de educación más que la población no migrante. En el resto de las regiones los resultados son más ambiguos. En el caso del Gran Buenos Aires (GBA), la población no migrante de entre 15 y 34 años tiene en promedio más años de educación. 
Mientras que lo contrario se observa en los grupos de edad de 45 a 65 años, donde los migrantes tienen en promedio 3 o más años de educación que la población nativa. En la región Pampeana, se observa el patrón inverso, los migrantes internos pertenecientes a los grupos de edad mas jóvenes tienen en promedio mas años de educación que la población local.

\section{Gráfico 6}
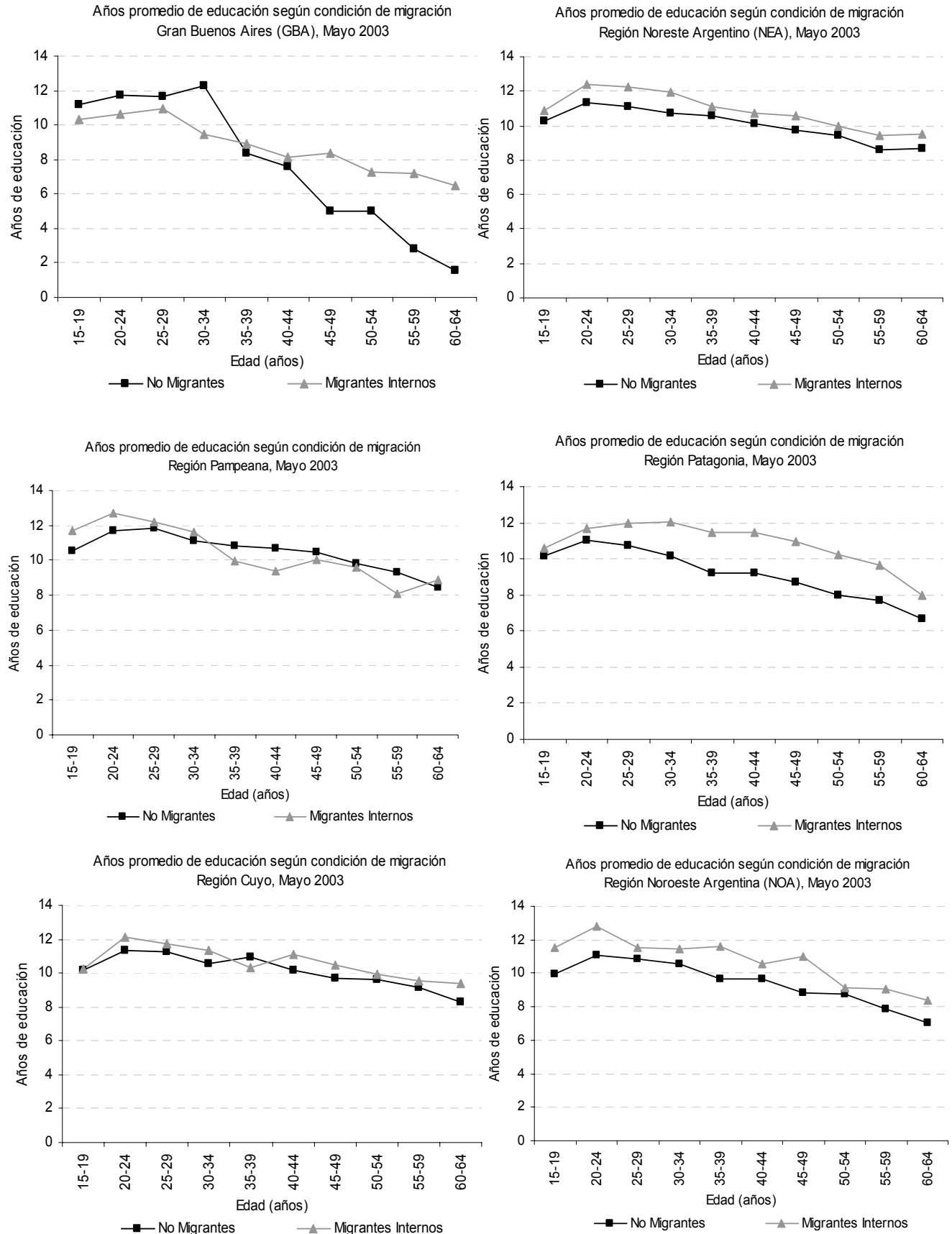

Fuente: Estimación propia en base a la Encuesta Permanente de Hogares (EPH), INDEC. 


\subsection{Estado ocupacional y de la fuerza de trabajo}

Entre las principales razones que explican la decisión de migrar de una persona, se encuentra la búsqueda de empleo o de mejores oportunidades en términos de salario y una mejor ocupación. Tanto los salarios como las tasas de empleo y desempleo determinan la dirección y los flujos migratorios netos. El análisis teórico pionero de las migraciones realizado por Todaro (1969) y Harris- Todaro (1970), enmarcan la decisión de migrar en la teoría del capital humano y proponen a los flujos migratorios como función del diferencial de ingresos entre las regiones de origen y destino y la probabilidad de obtener un empleo en el lugar de destino.

El Cuadro 14 muestra la población migrante y no migrante según su estado ocupacional. Como se observa en el cuadro, la tasa de desempleo de los migrantes internos es un punto porcentual inferior a la tasa de desempleo observada para los no migrantes. Sin embargo, este no es el caso de las personas que migraron recientemente, para los cuales se observa una tasa de desempleo 6 puntos superior a la del resto de la población. El porcentaje de personas inactivas que cambiaron su lugar de residencia en los últimos 5 años también resulta elevada en comparación con el resto de los migrantes internos ( $43 \%$ versus $35 \%$ para el total de migrantes internos).

Cuadro 14

Población en edad de trabajar según condición de migración y situación ocupacional Total de aglomerados urbanos, Onda Mayo 2003.

\begin{tabular}{|c|c|c|c|c|c|c|c|c|}
\hline \multirow[b]{2}{*}{ Condición de migración } & \multicolumn{6}{|c|}{ PEA } & \multirow[b]{2}{*}{$\begin{array}{c}\text { Total } \\
\text { Inactivos } \\
\end{array}$} & \multirow[b]{2}{*}{$\begin{array}{l}\text { Porcentaje de } \\
\text { Población tota }\end{array}$} \\
\hline & Total & $\begin{array}{l}\text { Porcentaje de } \\
\text { Población total }\end{array}$ & Ocupados & $\begin{array}{c}\text { Porcentaje } \\
\text { de PEA }\end{array}$ & Desocupados & $\begin{array}{c}\text { Porcentaje } \\
\text { de PEA }\end{array}$ & & \\
\hline Total & $10,114,648$ & 0.63 & $8,495,071$ & 0.84 & $1,619,577$ & 0.16 & $6,031,783$ & 0.37 \\
\hline No migrantes & $8,020,488$ & 0.62 & $6,723,906$ & 0.84 & $1,296,582$ & 0.16 & $4,924,309$ & 0.38 \\
\hline Migrantes internos & $2,094,160$ & 0.65 & $1,771,165$ & 0.85 & 322,995 & 0.15 & $1,107,474$ & 0.35 \\
\hline Migrantes de los últimos 5 años & 281,620 & 0.57 & 222,857 & 0.79 & 58,763 & 0.21 & 209,978 & 0.43 \\
\hline Migrantes de más de 5 años & $1,812,540$ & 0.67 & $1,548,308$ & 0.85 & 264,232 & 0.15 & 897,496 & 0.33 \\
\hline
\end{tabular}

Fuente: Estimación propia en base a la Encuesta Permanente de Hogares (EPH), INDEC.

En el Cuadro 15 se muestran las tasas de desempleo, según condición de migración de la población y región geográfica. La tasa de desempleo de los migrantes internos es menor para la población nativa en la región Pampeana y en la Patagónica. Sin embargo, cuando se tiene en cuenta si la persona migro recientemente o hace las de 6 años, lo que se observa es que en todas las regiones, el desempleo es mayor para los migrantes recientes, mientras que en el caso de las personas que migraron hace mas de 5 años, a la región Pampeana, Patagónica y NEA, la tasa de desempleo es menor que la de la población local y que el promedio de la región.

Cuadro 15

Desempleo según condición de migración y región geográfica

Total de aglomerados urbanos, Onda Mayo 2003.

\begin{tabular}{lcccccc}
\hline \hline & \multicolumn{7}{c}{ Región } \\
\cline { 2 - 7 } \multicolumn{1}{c}{ Condición de migración } & GBA & Pampeana & Cuyo & NOA & Patagonia & NEA \\
\hline Total & 0.112 & 0.103 & 0.066 & 0.084 & 0.076 & 0.053 \\
No migrantes & 0.112 & 0.104 & 0.063 & 0.083 & 0.081 & 0.054 \\
Migrantes internos & 0.115 & 0.099 & 0.077 & 0.091 & 0.068 & 0.048 \\
$\quad$ Migrantes de los últimos 5 años & 0.137 & 0.136 & 0.089 & 0.118 & 0.081 & 0.080 \\
Migrantes de más de 5 años & 0.113 & 0.091 & 0.074 & 0.084 & 0.064 & 0.038 \\
\hline
\end{tabular}

Fuente: Estimación propia en base a la Encuesta Permanente de Hogares (EPH), INDEC.

En cuanto a la duración del desempleo, entre los migrantes internos desocupados, quienes han migrado recientemente, la duración del desempleo es menor. Esto se observa tanto en el GBA, 
como en la región Pampeana y la Patagónica. En el caso de la región Cuyo, NEA y NOA, la duración del desempleo de los migrantes recientes es mayor (ver Cuadro A.5 del Apéndice).

El 3.98\% de los migrantes internos son trabajadores independientes o profesionales (el porcentaje es mayor para quienes migraron hace mas de 5 años). Respecto de la población no migrante, los migrantes recientes se encuentran ocupados en mayor proporción en grandes firmas $(33.84 \%)$, mientras que los trabajadores que migraron hace más de 5 años se encuentran principalmente empleados en el sector público (25\%). Un menor porcentaje de migrantes internos son empleadores. El 3\% de las personas que migraron en los últimos 5 años, son trabajadores sin ingreso, cifra superior al $1 \%$ observado para la población no migrante o quienes migraron hace mas de 5 años (Cuadro 16).

Cuadro 16

Población ocupada según condición de migración y sector económico

Total de aglomerados urbanos, Onda Mayo 2003.

\begin{tabular}{|c|c|c|c|c|c|c|c|}
\hline \multirow{3}{*}{ Condición de migración } & \multicolumn{4}{|c|}{ Trabajadores formales } & \multicolumn{3}{|c|}{ Trabajadores Informales } \\
\hline & \multirow[b]{2}{*}{ Empleador } & \multicolumn{2}{|c|}{ Trabajadores asalariados } & \multirow{2}{*}{$\begin{array}{l}\text { Independientes } \\
\text { Profesionales }\end{array}$} & \multirow{2}{*}{$\begin{array}{c}\text { Asalariado } \\
\text { Pequeñas firmas }\end{array}$} & \multirow{2}{*}{$\begin{array}{l}\text { Independientes } \\
\text { No calificados }\end{array}$} & \multirow{2}{*}{$\begin{array}{c}\text { Trabajadores } \\
\text { sin ingreso }\end{array}$} \\
\hline & & Grandes firmas & Sector Público & & & & \\
\hline Total & 3.61 & 28.60 & 22.46 & 3.51 & 20.97 & 19.72 & 1.12 \\
\hline No migrantes & 3.86 & 29.18 & 21.87 & 3.39 & 21.29 & 19.27 & 1.14 \\
\hline Migrantes internos & 2.63 & 26.41 & 24.69 & 3.98 & 19.78 & 21.44 & 1.07 \\
\hline Migrantes de los últimos 5 años & 2.02 & 33.84 & 20.13 & 3.67 & 18.36 & 18.86 & 3.12 \\
\hline Migrantes de más de 5 años & 2.72 & 25.35 & 25.34 & 4.03 & 19.98 & 21.81 & 0.78 \\
\hline
\end{tabular}

Fuente: Estimación propia en base a la Encuesta Permanente de Hogares (EPH), INDEC.

En cuando al sector de actividad (Cuadro 17) los migrantes internos están principalmente ocupados en el sector Construcción (11\%), Servicios y Transporte y Servicios no calificados y Administración Pública (9\%). También, entre las personas que han migrado en los últimos 5 años, se observa un mayor porcentaje de ocupados en el sector primario

Cuadro 17

Población ocupada según condición de migración y sector económico Total de aglomerados urbanos, Onda Mayo 2003.

\begin{tabular}{lcccccccccc}
\hline \hline \multicolumn{1}{c}{ Condición de migración } & $\begin{array}{c}\text { Sector } \\
\text { Primario }\end{array}$ & $\begin{array}{c}\text { Industria } \\
\text { básicas }\end{array}$ & $\begin{array}{c}\text { Industria alta } \\
\text { Tecnología }\end{array}$ & Construcción & Comercio & $\begin{array}{c}\text { Servicios y } \\
\text { Transporte }\end{array}$ & $\begin{array}{c}\text { Servicios } \\
\text { no calificados }\end{array}$ & $\begin{array}{c}\text { Administración } \\
\text { Pública }\end{array}$ & $\begin{array}{c}\text { Educación } \\
\text { y Salud }\end{array}$ & $\begin{array}{c}\text { Servicio } \\
\text { Doméstico }\end{array}$ \\
\hline Total & 1.44 & 6.20 & 7.06 & 8.48 & 21.83 & 7.78 & 9.15 & 8.38 & 22.30 & 7.38 \\
No migrantes & 1.37 & 6.41 & 7.26 & 7.60 & 22.32 & 7.83 & 9.45 & 8.04 & 22.70 & 7.00 \\
Migrantes internos & 1.70 & 5.44 & 6.31 & 11.76 & 19.98 & 7.59 & 7.99 & 9.65 & 20.78 & 8.81 \\
Migrantes de los últimos 5 años & 2.49 & 2.89 & 5.44 & 9.07 & 22.93 & 9.60 & 13.42 & 9.39 & 18.39 & 6.38 \\
Migrantes de más de 5 años & 1.58 & 5.83 & 6.44 & 12.17 & 19.53 & 7.28 & 7.16 & 9.69 & 21.14 & 9.18 \\
\hline
\end{tabular}

Fuente: Estimación propia en base a la Encuesta Permanente de Hogares (EPH), INDEC.

El promedio de horas trabajadas por los migrantes internos es mayor que para la población no migrante. También se observa que mientras que el $80 \%$ de la población que no ha migrado tiene una ocupación permanente, en el caso de los migrantes internos este porcentaje es menor (74\%). Consecuentemente, también es menor el porcentaje de migrantes internos con derechos a percibir una jubilación o a disponer de un seguro de salud (Cuadro 18).

Cuadro 18

Población ocupada según condición de migración y características laborales Total de aglomerados urbanos, Onda Mayo 2003.

\begin{tabular}{lcccc}
\hline \hline \multirow{2}{*}{ Condición de migración } & \multicolumn{4}{c}{ Características laborales } \\
\cline { 2 - 5 } & $\begin{array}{c}\text { Horas } \\
\text { Trabajadas }\end{array}$ & $\begin{array}{c}\text { Trabajo } \\
\text { permanente }\end{array}$ & $\begin{array}{c}\text { Derecho a } \\
\text { Jubilación }\end{array}$ & $\begin{array}{c}\text { Seguro de } \\
\text { Salud }\end{array}$ \\
\hline Total & 39.2 & 79.3 & 54.5 & 55.4 \\
No migrantes & 39.1 & 80.0 & 54.7 & 55.6 \\
Migrantes internos & 39.5 & 76.6 & 53.8 & 54.6 \\
$\quad$ Migrantes de los últimos 5 años & 40.6 & 74.0 & 51.1 & 55.6 \\
Migrantes de más de 5 años & 39.4 & 76.9 & 54.2 & 55.1 \\
\hline
\end{tabular}


Fuente: Estimación propia en base a la Encuesta Permanente de Hogares (EPH), INDEC.

\subsection{Nivel de ingresos y migraciones internas}

Existen importantes diferencias en materia de ingresos entre la población migrante y no migrante. Los diferenciales de ingresos entre las regiones de origen y destino tienen un impacto positivo en la decisión de migrar. Sin embargo, como se observa en el Cuadro 19, las diferencias de ingreso entre la población que ha migrado y la población no migrante persiste.

Así, el ingreso individual promedio de los no migrantes ( $\$ 438$ mensuales) es mayor que el ingreso de los migrantes internos ( $\$ 410$ mensuales). Sin embargo, si el análisis se realiza por región geográfica, lo que se observa es que a excepción del Gran Buenos Aires, el ingreso promedio de los migrantes internos es superior al de los no migrantes (especialmente en la región Patagónica y el NEA). Contrariamente a lo observado en nuestro país, la evidencia para Estados Unidos muestra que los salarios de los migrantes crecen más que los de la población nativa pero nunca llegan a alcanzar su nivel (Borjas, 2000).

A partir del Cuadro 19, puede observarse que la brecha salarial entre hombre y mujeres es mayor entre los migrantes internos, especialmente para los migrantes recientes, donde el ingreso individual de los hombres es un $60 \%$ superior al de las mujeres (y un 55\% superior para el total de migrantes internos).

Cuadro 19

Ingreso individual de la población entre 25 y 55 años según condición de migración Total de aglomerados urbanos y zonas geográficas, Onda Mayo 2003.

\begin{tabular}{|c|c|c|c|c|c|c|c|c|c|}
\hline \multirow[b]{2}{*}{ Condición de migración } & \multirow[b]{2}{*}{ Total } & \multicolumn{2}{|c|}{ Género } & \multicolumn{6}{|c|}{ Región } \\
\hline & & Mujeres & Hombres & GBA & Pampeana & Cuyo & NOA & Patagonia & NEA \\
\hline Total & 438.2 & 293.3 & 610.9 & 501.4 & 383.0 & 337.8 & 305.1 & 598.0 & 297.4 \\
\hline No migrantes & 438.2 & 303.6 & 618.7 & 541.4 & 376.6 & 327.8 & 286.8 & 464.4 & 274.0 \\
\hline Migrantes internos & 410.5 & 258.5 & 585.6 & 373.9 & 411.3 & 374.1 & 365.5 & 751.8 & 380.1 \\
\hline Migrantes de los últimos 5 años & 434.9 & 244.1 & 613.7 & 421.3 & 424.1 & 390.1 & 343.9 & 711.6 & 267.6 \\
\hline Migrantes de más de 5 años & 407.3 & 260.2 & 581.4 & 370.1 & 409.3 & 369.8 & 370.2 & 761.6 & 403.9 \\
\hline
\end{tabular}

Fuente: Estimación propia en base a la Encuesta Permanente de Hogares (EPH), INDEC.

En el panel de Gráficos 7 se grafican los ingresos per capita familiar según región geográfica, para los hogares cuyos jefes tienen 25 años o más. La región Patagónica y NEA los ingresos per capita familiar de los hogares que han migrado son superiores al ingreso per capita familiar de los hogares que no han cambiado su lugar de residencia. Esto hecho, se observa para todos los grupos de edad, aunque la mayor dispersión de ingresos corresponde a la región patagónica.

En el caso del GBA, la relación es inversa, a excepción de los hogares con jefes de 25 a 29 años de edad, los ingresos per capita familiar son superiores en los hogares nativos. La región NOA, los ingresos per capita familiar de los migrantes internos son mayores en los hogares mas jóvenes, mientras que en la región Cuyo, los hogares con jefes de 45 años o mas tienen ingreso per capita familiar superiores al de los hogares que no han migrado.

En la región Pampeana, en cambio, si bien para los hogares con jefes de hogar menores de 49 años, los ingresos per capita familiar son mayores que los ingresos de los hogares no migrantes, las diferencias no son significativas (en promedio, menores a los $\$ 50$ pesos mensuales). 
Gráfico 7

Ingreso per capita familiar según región geográfica y condición de migración Jefes de hogar mayores de 25 años de edad, Onda Mayo 2003
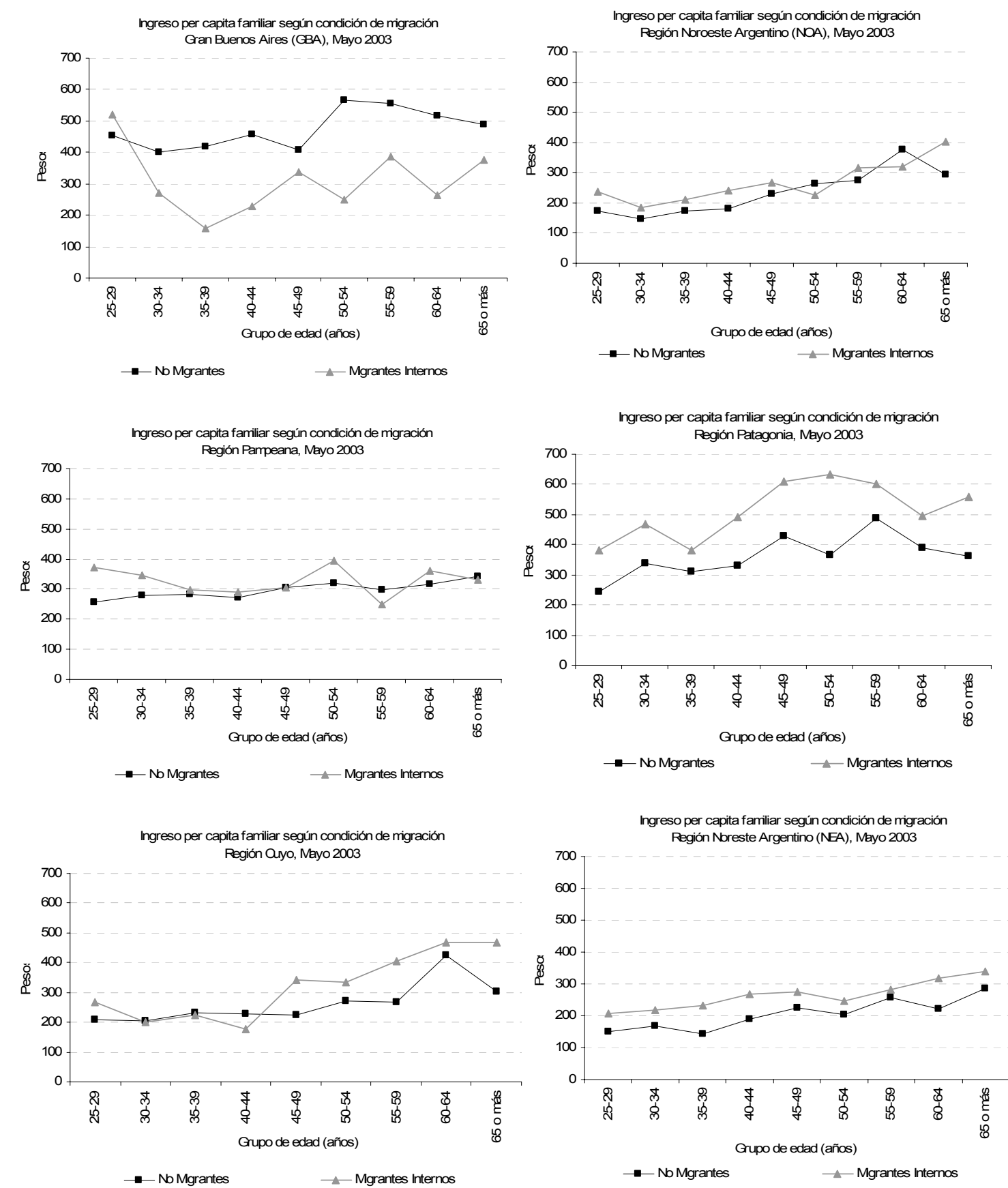

Fuente: Estimación propia en base a la Encuesta Permanente de Hogares (EPH), INDEC. 


\subsection{Pobreza y asistencia social de la población migrante y no migrante}

En ciertas ocasiones, la decisión de migrar se ve influenciada por la situación de pobreza en que los individuos y sus hogares se encuentran en su lugar de origen. En este caso, la decisión de migrar se corresponde con la búsqueda de ciertas mejoras en el bienestar debido a un mayor acceso a servicios de salud y educación pública, programas de alimentación y de asistencia social, planes de vivienda o el acceso a tierras y a trabajos precarios que permiten a los individuos y sus hogares superar su situación de pobreza original.

El Cuadro 20 muestra el porcentaje de personas pobres según condición de migración. Mientras que el $31 \%$ de la población no migrante vive en situación de pobreza extrema, solo el $25 \%$ de los migrantes internos se encuentra en esta condición. El porcentaje es menor entre los migrantes recientes $(21 \%)$, respecto de las personas que migraron hace más de 5 años. Resultados similares se observan al considerar la pobreza moderada, así como también las brechas de pobreza y la profundidad de la pobreza. Estas observaciones son válidas en todas las regiones geográficas (ver Cuadro 21). Aunque las diferencias en el porcentajes de migrantes (especialmente los migrantes recientes) y no migrantes que viven en situación de pobreza o indigencia es mayor en la región Pampeada, NOA y NEA. En el Cuadro A.6 del Apéndice, se describen algunas características habitacionales de los hogares.

Cuadro 20

Población total según condición de migración y situación de pobreza

Total de aglomerados urbanos, Onda Mayo 2003.

\begin{tabular}{lcccccccc}
\hline \hline \multirow{2}{*}{ Condición de migración } & \multicolumn{3}{c}{ Pobreza extrema } & & \multicolumn{3}{c}{ Pobreza moderada } \\
\cline { 2 - 3 } & Headcount & Poverty gap & & Headcount Poverty gap \\
& FGT(0) & FGT(1) & FGT(2) & & FGT(0) & FGT(1) & FGT(2) \\
\hline Total & 30.0 & 15.6 & 11.3 & & 57.1 & 31.4 & 21.9 \\
No migrantes & 31.0 & 16.0 & 11.6 & & 57.8 & 32.1 & 22.5 \\
Migrantes internos & 25.4 & 13.3 & 9.9 & & 53.7 & 28.2 & 19.3 \\
$\quad$ Migrantes de los últimos 5 años & 21.8 & 10.7 & 8.1 & & 50.6 & 26.0 & 17.1 \\
$\quad$ Migrantes de más de 5 años & 26.0 & 13.8 & 10.2 & & 54.3 & 28.6 & 19.7 \\
\hline
\end{tabular}

Fuente: Estimación propia en base a la Encuesta Permanente de Hogares (EPH), INDEC.

Cuadro 21

Población total según condición de migración y situación de pobreza

Zonas geográficas, Onda Mayo 2003.

\begin{tabular}{lcccccc}
\hline \hline \multirow{2}{*}{ Condición de migración } & \multicolumn{5}{c}{ Región Georgráfica } \\
\cline { 2 - 7 } & GBA & Pampeana & Cuyo & NOA Patagonia & NEA \\
\hline Pobreza Extrema & 24.7 & 36.9 & 31.2 & 34.1 & 21.8 & 40.3 \\
Total & 25.0 & 37.7 & 32.3 & 35.5 & 23.2 & 42.6 \\
No migrantes & 23.4 & 32.0 & 25.5 & 26.5 & 18.8 & 26.9 \\
Migrantes internos & 23.6 & 17.1 & 25.9 & 23.2 & 15.9 & 27.5 \\
$\quad$ Migrantes de los últimos 5 años & 23.3 & 35.1 & 25.3 & 27.5 & 19.7 & 26.7 \\
$\quad$ Migrantes de más de 5 años & & & & & & \\
Pobreza Moderada & 51.4 & 61.2 & 60.7 & 68.1 & 44.2 & 71.7 \\
Total & 50.6 & 62.2 & 61.8 & 70.2 & 48.1 & 74.5 \\
No migrantes & 55.2 & 54.6 & 54.8 & 56.3 & 35.9 & 55.1 \\
$\quad$ Migrantes internos & 60.3 & 45.9 & 53.4 & 45.3 & 31.1 & 52.7 \\
$\quad$ Migrantes de los últimos 5 años & 54.5 & 56.4 & 55.3 & 59.4 & 37.4 & 55.9 \\
$\quad$ Migrantes de más de 5 años & 54.5 &
\end{tabular}

Fuente: Estimación propia en base a la Encuesta Permanente de Hogares (EPH), INDEC.

Finalmente, es importante ver que porcentaje de los migrantes internos percibe planes de asistencia social. La evidencia encontrada en la literatura sobre la atracción que los programas de asistencia social tienen sobre la población migrantes es ambigua. En Argentina, se observa que el 
porcentaje de migrantes internos que recibe planes sociales es relativamente mayor (12\%) respecto a la población no migrante (10\%). Sin embargo, se observan diferencias importantes en la percepción de programas sociales por parte de los migrantes recientes (solo el 5.8\%) y las personas que tomaron su decisión de migración hace más de 5 años (13\%). Según zonas geográficas, solo en la región Cuyo se observa el patrón inverso.

Cuadro 22

Percepción de programas sociales según condición de migración

Zonas geográficas, Onda Mayo 2003.

\begin{tabular}{lccccccc}
\hline \hline & & \multicolumn{7}{c}{ Región } \\
\cline { 3 - 8 } & Total & GBA & Pampeana & Cuyo & NOA & Patagonia & NEA \\
\hline Total & 10.6 & 10.0 & 9.2 & 8.6 & 16.7 & 7.6 & 19.2 \\
No migrantes & 10.0 & 8.5 & 8.9 & 8.6 & 18.0 & 9.2 & 21.9 \\
Migrantes internos & 12.2 & 14.0 & 10.2 & 8.6 & 13.2 & 5.9 & 11.9 \\
$\quad$ Migrantes de los últimos 5 años & 5.8 & 4.3 & 6.2 & 9.6 & 6.6 & 2.9 & 7.3 \\
Migrantes de más de 5 años & 12.9 & 14.5 & 10.7 & 8.4 & 14.3 & 6.4 & 12.9 \\
\hline
\end{tabular}

Fuente: Estimación propia en base a la Encuesta Permanente de Hogares (EPH), INDEC.

Hecha esta caracterización de la población migrante, en la sección siguiente se presentaran algunos aspectos teóricos básicos para la estimación de los determinantes de las migraciones internas en argentina.

\section{MARCO TEÓRICO Y Metodología de ESTIMACIÓN}

El marco básico para determinar la decisión individual de un individuo al migrar se basa en un modelo de maximización de utilidad. Este proceso de maximización, que supone racionalidad en la toma de decisiones, es el que definirá el resultado individual de migrar a otra región o permanecer en la provincia donde vive actualmente. Esta decisión depende de varios factores, que determinan la utilidad esperada en cada región. En este trabajo, se asume que la utilidad es una función de las características individuales, características regionales y políticas públicas que llevan adelantes los gobiernos provinciales.

Los individuos maximizan su utilidad $\left(u_{i}\right)$ sobre un conjunto de provincias, $k=1,2 \ldots K$. Dentro de una determinada provincia, la función de utilidad indirecta básica puede expresarse como:

$$
u_{i}^{k}=u\left(X_{i}, A^{k}, P^{k}\right)
$$

Donde $\mathrm{X}_{\mathrm{i}}$, representa características de los individuos, $A^{k}$ denota las amenidades de la provincia $k$ $y P^{k}$ representa las políticas públicas en la provincia $k$.

La utilidad en la provincia de origen se denota como $u_{i}^{k}$ y la utilidad esperada en la provincia de destino se expresa como $u_{i}^{k^{\prime}}$. La utilidad en cada región también depende de un vector de características individuales observables, $X_{i}$. Asimismo la función también indica las preferencias por las características provinciales observables $A^{k}$ que tienen los individuos. Es importante notar que tanto las amenidades provinciales $(A)$ como las políticas públicas $(\mathrm{P})$ afectan uniformemente la utilidad de los individuos entre provincias (por ej., los niveles de contaminación o de gasto publico afecta de igual modo a todas las personas que viven en una misma provincia).

Suponiendo que los individuos maximizan su utilidad esperada, una persona migrará si su utilidad esperada al movilizarse hacia una nueva provincia, denotada por $E\left(u_{i}^{k^{\prime}}\right)$, es mayor que la utilidad 
esperada de permanecer en la provincia de residencia actual, $E\left(u_{i}^{k}\right)$. La utilidad esperada de migrar o no migrar puede definirse como:

$$
\begin{aligned}
& \left.E\left(u_{i}^{k}\right)=\beta^{k} X_{i}+\gamma^{k} A_{i}^{k}+\delta^{k} P_{i}^{k}+\varepsilon_{i}^{k}\right) \\
& \left.E\left(u_{i}^{k^{\prime}}\right)=\beta^{k^{\prime}} X_{i}+\gamma^{k^{\prime}} A_{i}^{k^{\prime}}+\delta^{k^{\prime}} P_{i}^{k^{\prime}}+\varepsilon_{i}^{k^{\prime}}\right)
\end{aligned}
$$

donde $\varepsilon^{k}$ y $\varepsilon^{k^{\prime}}$ están conjunta y normalmente distribuidas con media cero y varianza $\sigma_{k}^{2}$ y $\sigma_{k^{\prime}}^{2}$. Un individuo decide migrar si, los costos de migración netos:

$$
M_{i}^{*}=E\left(u_{i}^{k^{\prime}}\right)-E\left(u_{i}^{k}\right)>0
$$

Claramente la función indicadora $M_{i}^{*}$ es inobservable. Sin embargo, a partir de las ecuaciones (2), (3) y (4), $M_{i}^{*}$ puede definirse como:

$$
\begin{aligned}
& M_{i}^{*}=E\left(u_{i}^{k^{\prime}}\right)-E\left(u_{i}^{k}\right) \\
& M_{i}^{*}=\beta^{k^{\prime}} X_{i}-\beta^{k} X_{i}+\gamma^{k^{\prime}} A_{i}^{k^{\prime}}-\gamma^{k} A_{i}^{k}+\delta^{k^{\prime}} P_{i}^{k^{\prime}}-\delta^{k} P_{i}^{k}+\varepsilon_{i}^{k^{\prime}}-\varepsilon_{i}^{k} \\
& M_{i}^{*}=W_{i} \pi+e_{i}
\end{aligned}
$$

Definiendo $M=1$ cuando $M_{i}^{*}>0$, cuando el individuo toma la decisión de migar y, $M=0$ si $M_{i}^{*} \leq 0$, cuando la persona permanece en la provincia de residencia actual, entonces, la ecuación (6) puede verse como un modelo probit sobre la decisión de migrar. Nótese que la matriz $\mathrm{W}$ puede descomponerse en una matriz de características individuales y regionales.

Estimar la decisión de migrar de la ecuación (6) tiene la ventaja de que provee evidencia tanto sobre el rol de las características individuales $\left(X_{i}\right)$ como características propias de cada provincia $\left(A^{k}\right)$ en la decisión de migrar que toma un individuo y las políticas públicas $\left(P^{k}\right)$

Como se mencionó anteriormente, se supone que el individuo compara las utilidades esperadas de una y otra provincia, por ejemplo, a través de los salarios e ingresos en una y otra provincia, los gastos públicos en educación y salud, etc. Si estas diferencias resultan positivas, el individuo decidirá mudarse de localidad. La ecuación (6) puede reescribirse y estimarse mediante un modelo probit de la siguiente manera:

$$
M_{i}^{*}=X_{i} \pi+A^{k} \gamma+\delta P^{k}+e \quad \text { donde } e \sim N(0,1)
$$

La probabilidad de que un individuo decida migrar es:

$$
\operatorname{Pr} o b\left(M_{i}=1\right)=\phi\left(X_{i} \pi+A^{k} \gamma+\delta P^{k}\right)
$$

donde $\phi($.$) es la función de densidad acumulada normal estandarizada. La probabilidad que una$ persona elija quedarse en su provincia de residencia actual es simplemente: 


$$
\operatorname{Pr} \operatorname{ob}\left(M_{i}=0\right)=1-\phi\left(X_{i} \pi+A^{k} \gamma+\delta P^{k}\right)
$$

En la sección siguiente, se presentan los resultados de las estimaciones de la probabilidad de migrar de las personas, teniendo en cuenta características individuales y regionales.

\section{ReSUltado de LAS Estimaciones}

\subsection{Características individuales y decisiones de migración}

La propensión de migrar varía con las características individuales tales como en sexo, la edad, el estado civil y la composición familiar, el nivel educativo o la situación ocupacional. En el Cuadro 23, se presentan los resultados de las estimaciones realizadas acerca de la probabilidad de ser migrante interno dadas las características individuales de las personas mayores a 28 años ${ }^{15}$.

Como se observa en el cuadro, la variable hombre (que toma valor 1 para los hombres), si bien presenta el signo esperado, no es significativa en ninguno de los modelos estimados. Esto indica que no hay diferencias de género en la probabilidad de ser migrante interno. En cuanto a la edad de las personas (variable edad), es siempre positiva y significativa, mientras que el cuadrado de edad tiene signo negativo, indicando que la propensión de migrar es mayor entre las personas jóvenes, crece hasta la mediana edad y disminuye con la edad de retiro de las personas.

En la mayoría de la literatura los resultados indican que los individuos casados o los hogares con hijos tienen una probabilidad menor de migrar que los individuos solteros o las parejas sin hijos, debido a los mayores costos de movilidad implicados en el traslado del hogar (Greenwood 1975 y 1985 y Van Dijk 1989). En los modelos estimados, la variable correspondiente al estado civil de las personas (Casado), no resulta significativa. En cambio, se observa que la variable que indica la presencia de hijos en el hogar al momento de migrar, es negativa y significativa. En este caso, la probabilidad de migrar hacia otra provincia, disminuye cuando hay hijos menores de edad presentes en el hogar.

En el modelo I, se incluye la variable años de educación, que tiene signo negativo y es significativa, lo cual indica que son las personas menos educadas las que tienen una mayor propensión a migrar. En los modelos II, III y IV, se introdujo dummies por nivel educativo. En concordancia con el resultado anterior, en todos los modelos, las dummies por nivel educativo son negativas y significativas, indicando que las personas sin educación o estudios primarios incompletos tienen mayor probabilidad de migrar que las personas con más educación. En otras palabras, la probabilidad de ser migrante interno decrece a medida que aumenta el nivel educativo de las personas.

En el modelo III, se incorporaron variables referidas al estado ocupacional de la persona y la tenencia o no de una vivienda propia. Como se observa, el hecho que la persona se encuentre desocupada aumenta la probabilidad de ser migrante, mientras que el hecho de contar con una vivienda propia, tiene un impacto negativo sobre la decisión de migrar. En muchos estudios, los trabajadores desempleados han mostrado propensiones más altas de migrar que los trabajadores empleados. Herzog (1993), resume un conjunto de trabajos que usan datos para los Estados Unidos, el Reino Unido y los Países Bajos, la variable dependiente es la probabilidad relativa de migrar y concluyen que la condición de desempleado de una persona aumenta de manera importante la probabilidad de migrar.

\footnotetext{
${ }^{15}$ En el Cuadro A.7 del Apéndice, se incluyen descripción de las variables utilizadas en las estimaciones.
} 
Finalmente, en el modelo IV, se incorporaron dummies regionales. Como se observa, respecto de la población residente en el GBA, la probabilidad de ser migrante interno es menor en las regiones Pampeana, NOA, NEA y Cuyo y solo es mayor para la región Patagónica, que como se observaba en el Gráfico 3, incluye a las dos provincias con las mayores tasas de inmigración neta positiva, como son Santa Cruz y Tierra del Fuego.

Cuadro 23

Modelo Probit para la probabilidad de ser migrante interno. Población 28 años o más.

\begin{tabular}{|c|c|c|c|c|}
\hline Variables & Modelo I & Modelo II & $\begin{array}{l}\text { Modelo III } \\
\end{array}$ & $\begin{array}{l}\text { Modelo IV } \\
\end{array}$ \\
\hline Hombre & $\begin{array}{l}0.002 \\
(0.07)\end{array}$ & $\begin{array}{l}-0.001 \\
(0.04)\end{array}$ & $\begin{array}{l}0.068 \\
(1.04)\end{array}$ & $\begin{array}{l}0.045 \\
(1.48)\end{array}$ \\
\hline Edad & $\begin{array}{l}0.052 \\
(6.23)^{\star *}\end{array}$ & $\begin{array}{l}0.051 \\
(6.14)^{\star *}\end{array}$ & $\begin{array}{l}0.048 \\
(4.99)^{* *}\end{array}$ & $\begin{array}{c}0.051 \\
(7.32)^{\star *}\end{array}$ \\
\hline Edad2 & $\begin{array}{l}-0.0004 \\
(5.31)^{\star *}\end{array}$ & $\begin{array}{l}-0.0004 \\
(5.30)^{\star *}\end{array}$ & $\begin{array}{l}-0.00041 \\
(4.80)^{\star *}\end{array}$ & $\begin{array}{l}-0.00042 \\
(6.63)^{\star *}\end{array}$ \\
\hline Años de educación & $\begin{array}{c}-0.054 \\
(12.74)^{\star *}\end{array}$ & & & \\
\hline Casado & $\begin{array}{l}0.014 \\
(0.29)\end{array}$ & $\begin{array}{l}0.015 \\
(0.31)\end{array}$ & $\begin{array}{l}-0.015 \\
(0.24)\end{array}$ & $\begin{array}{l}0.053 \\
(1.57)\end{array}$ \\
\hline Hijos en el hogar & $\begin{array}{c}0.124 \\
(2.24)^{\star}\end{array}$ & $\begin{array}{c}0.122 \\
(2.18)^{*}\end{array}$ & & \\
\hline Primaria completa & & $\begin{array}{l}-0.298 \\
(5.35)^{\star \star}\end{array}$ & $\begin{array}{l}-0.305 \\
(4.76)^{\star *}\end{array}$ & $\begin{array}{l}-0.297 \\
(6.21)^{* *}\end{array}$ \\
\hline Secundaria incompleta & & $\begin{array}{l}-0.490 \\
(7.64)^{\star \star}\end{array}$ & $\begin{array}{l}-0.545 \\
(7.22)^{* *}\end{array}$ & $\begin{array}{l}-0.493 \\
(8.72)^{* *}\end{array}$ \\
\hline Secundaria completa & & $\begin{array}{c}-0.683 \\
(11.12)^{\star *}\end{array}$ & $\begin{array}{l}-0.666 \\
(9.10)^{\star *}\end{array}$ & $\begin{array}{c}-0.635 \\
(11.85)^{\star *}\end{array}$ \\
\hline Universitaria incompleta & & $\begin{array}{l}-0.692 \\
(9.16)^{\star *}\end{array}$ & $\begin{array}{l}-0.661 \\
(7.12)^{\star *}\end{array}$ & $\begin{array}{l}-0.650 \\
(9.68)^{\star *}\end{array}$ \\
\hline Universitaria completa & & $\begin{array}{c}-0.705 \\
(10.83)^{\star *}\end{array}$ & $\begin{array}{l}-0.634 \\
(8.27)^{\star *}\end{array}$ & $\begin{array}{c}-0.677 \\
(11.84)^{\star *}\end{array}$ \\
\hline Desempleado & & & $\begin{array}{c}0.158 \\
(1.99)^{*}\end{array}$ & \\
\hline Propietario de Vivienda & & & $\begin{array}{l}-0.157 \\
(3.30)^{* *}\end{array}$ & \\
\hline Región Pampeana & & & & $\begin{array}{l}-0.307 \\
(8.76)^{\star \star}\end{array}$ \\
\hline Región Cuyo & & & & $\begin{array}{l}-0.133 \\
(3.32)^{\star \star}\end{array}$ \\
\hline Región NOA & & & & $\begin{array}{l}-0.064 \\
(2.06)^{*}\end{array}$ \\
\hline Región Patagonia & & & & $\begin{array}{c}0.600 \\
(18.45)^{* *}\end{array}$ \\
\hline Región NEA & & & & $\begin{array}{l}-0.259 \\
(7.17)^{\star *}\end{array}$ \\
\hline Constante & $\begin{array}{c}-1.67 \\
(8.10)^{\star \star} \\
\end{array}$ & $\begin{array}{c}-1.708 \\
(8.20)^{\star *}\end{array}$ & $\begin{array}{c}-1.346 \\
(5.20)^{\star *} \\
\end{array}$ & $\begin{array}{c}-1.577 \\
(8.68)^{\star *}\end{array}$ \\
\hline $\begin{array}{l}\text { Nro Observaciones } \\
\text { Pseudo R2 }\end{array}$ & $\begin{array}{l}21822 \\
0.0411\end{array}$ & $\begin{array}{l}21834 \\
0.0444\end{array}$ & $\begin{array}{l}14564 \\
0.0331\end{array}$ & $\begin{array}{l}27729 \\
0.0494\end{array}$ \\
\hline
\end{tabular}

Robust z statistics in parentheses- * significant at 5\%; ** significant at $1 \%$ Fuente: estimación propia sobre la base de la EPH, Mayo 2003. 


\subsection{Características regionales, políticas públicas y decisiones de migración}

Además de las características individuales analizadas en la sección anterior para estimar la propensión a migrar de las personas, en esta sección se incluyen en los modelos antes estimados características de las provincias, como su grado de urbanización y desarrollo, características climáticas, disponibilidad de recursos turísticos y locales y variables de política pública, como los gastos provinciales en educación, vivienda pública, etc.

En el Cuadro 24, se presentan los resultados de las estimaciones. Como se observa en todos los modelos estimados, las diferencias en los salarios entre regiones se tienen una influencia fuertemente positiva en las decisiones de migrar de los individuos. También se observa una preferencia de las personas por migrar a provincias con mayor población o hacia los grandes centros urbanos, representando esto los posibles beneficios derivados de la aglomeración. Sin embargo, cuando se introduce el tamaño de la población elevada al cuadrado, se observa que la probabilidad de migrar hacia localidades densamente pobladas es negativa. Esto puede observarse a partir del signo negativo que toma la variable Población2, aunque, no en todos los modelos estimados esta variable es significativa.

En el Modelo I, se incorporan variables relacionadas con la seguridad de las regiones. Como se observa, tanto los accidentes de tránsito, como los crímenes a la propiedad o la violencia física hacia las personas afectan negativamente la decisión de migrar a una región. Estas tres variables presentan signos negativos esperados, aunque solo la mayor frecuencia de accidentes de tránsito y la agresión o violencia hacia las personas resultan significativas. Los crímenes a la propiedad, no es una variable significativa en la decisión de migrar de las personas.

Con el objetivo de observar la presencia de migraciones inducidas por políticas públicas y detectar cual de los elementos de política publica tiene mayor impacto sobre las decisiones de migrar de los individuos, en el Modelo II se incluyen variables sobre gastos provinciales. Entre ellos los gastos per capita en educación (educación básica, superior y universitaria, cultura y ciencia y técnica), programas de empleo y seguros de desempleo y gastos per capita en vivienda y urbanismo. Contrariamente a lo esperado, los gastos en educación influyen negativamente en la decisión de migración a una región. Una posible explicación para este resultado es que la población bajo estudio (personas mayores de 28 años de edad) han finalizado sus estudios y formación educativa, de modo que los gastos en educación que realizan las provincias no son un factor que influencia su decisión de re-localización. Los gastos per capita en programas de empleo y seguros de desempleo que realizan las provincias, si bien presentan el signo esperado, no resultan significativos. En cambio, si es mayor la probabilidad de migrar a aquellas provincias en las cuales los gastos en vivienda pública y urbanismo son mayores.

En el Modelo II, también se incluyo una variable que refleja el residuo fiscal per capita de cada provincia $^{16}$. Esta variable busca captar el saldo neto que cada provincia obtiene luego de aportar y recibir, mediante los mecanismos de transferencia (por ejemplo la coparticipación de impuestos), al gobierno nacional. Este residuo fiscal es negativo si la provincia aporta más fondos de los que recibe por coparticipación del gobierno Nacional, (este es el caso de las provincias de Buenos Aires, Córdoba y Santa Fe). Las provincias más rezagadas (entre ellas: Santa Cruz, Tierra del Fuego, Catamarca, La Rioja, Santiago del Estero) son las que más se ven beneficiadas y recibiendo más ingresos de los que aportan, lo cual implica mayores fondos para gasto público. Como se observa en las columnas III y IV, el residuo fiscal influencia positivamente la probabilidad de migrar. Si bien el efecto es muy bajo, en ambos modelos, la esta variable resulta positiva y significativa.

\footnotetext{
${ }^{16}$ Una estimación del Residuo fiscal per capita por provincia puede encontrarse en el libro "La Distribución del Ingreso en Argentina", en el capítulo V.3 "Efectos de la política fiscal Nacional sobre la distribución regional y personal del ingreso", por Artana y Moskovitz.
} 
Además de las variables anteriores, en el Modelo IV, se incluyeron variables relacionadas con características de las regiones, como variables climáticas, una variable que refleja el grado de urbanización y el atractivo turístico de cada provincia. Las variables de tipo climáticas como la humedad de la región, temperatura máxima o mínima anual de una localidad, han demostrado tener en distintos estudios, una importante influencia en las decisiones de migración de las personas. Sin embargo, las estimaciones para nuestro país indican que tanto la temperatura media anual como las precipitaciones anuales no son variables que afectan las decisiones de relocalización de la población al interior de nuestro país.

Para reflejar el grado de urbanización de cada provincia, se incluyo una variable que representa el porcentaje de rutas y caminos sin pavimentar en cada provincia. Como se observa, la probabilidad de migrar se relaciona negativamente con el porcentaje de caminos sin pavimentar de una provincia, indicando una preferencia de los migrantes internos a trasladarse a provincias más urbanizadas y con mayor infraestructura.

Por último, como una característica adicional de cada provincia, se introdujo un indicador de los recursos turísticos disponibles en cada una de ellas. La estimación de esta variable fue realizada por Porto N. (2004). Según los resultados presentados en su trabajo, los recursos turísticos de las provincias argentinas presentan un fuerte contenido de recursos naturales (respecto de otros factores como recursos históricos, recursos de capital, trabajo calificado, etc.), siendo superior en las provincias de Buenos Aires, Chubut, La Pampa, Tierra del Fuego, Neuquén, Río Negro, San Juan y Santa Cruz. De acuerdo a los resultados del Modelo IV, la probabilidad de migrar a otra provincia, esta positivamente relacionada con la disponibilidad de recursos turísticos de las provincias. Según los resultados presentados por Porto, la mayoría de las provincias con alto PBI turístico presentan un contenido factorial dominante de recursos naturales, de modo que el entorno geográfico es el que genera la ventaja comparativa en Argentina, generando un fuerte incentivo para el traslado y la concentración de la población migrante hacia esas regiones. 
Cuadro 24

Modelo Probit para la probabilidad de ser migrante interno, características individuales y regionales. Población 28 años o más.

\begin{tabular}{|c|c|c|c|c|}
\hline Variables & Modelo I & Modelo II & Modelo III & Modelo IV \\
\hline Hombre & $\begin{array}{l}0.048 \\
(1.55)\end{array}$ & $\begin{array}{l}0.048 \\
(1.56)\end{array}$ & $\begin{array}{l}0.047 \\
(1.55)\end{array}$ & $\begin{array}{c}0.052 \\
(2.03)^{*}\end{array}$ \\
\hline Edad & $\begin{array}{c}0.051 \\
(7.42)^{* *}\end{array}$ & $\begin{array}{c}0.051 \\
(7.41)^{\star *}\end{array}$ & $\begin{array}{c}0.051 \\
(7.43)^{\star *}\end{array}$ & $\begin{array}{c}0.042 \\
(7.18)^{* *}\end{array}$ \\
\hline Edad2 & $\begin{array}{c}-0.00042 \\
(6.63)^{\star *}\end{array}$ & $\begin{array}{c}-0.00043 \\
(6.62)^{\star *}\end{array}$ & $\begin{array}{c}-0.00041 \\
(6.65)^{\star *}\end{array}$ & $\begin{array}{l}-0.0004 \\
(6.27)^{\star *}\end{array}$ \\
\hline Años de educación & $\begin{array}{c}-0.05 \\
(13.50)^{\star *}\end{array}$ & $\begin{array}{c}-0.05 \\
(13.45)^{\star *}\end{array}$ & $\begin{array}{c}-0.051 \\
(13.52)^{\star *}\end{array}$ & \\
\hline Primaria completa & & & & $\begin{array}{c}-0.161 \\
(4.10)^{\star *}\end{array}$ \\
\hline Secundaria incompleta & & & & $\begin{array}{c}-0.249 \\
(5.38)^{\star *}\end{array}$ \\
\hline Secundaria completa & & & & $\begin{array}{c}-0.366 \\
(8.19)^{\star *}\end{array}$ \\
\hline Universitaria incompleta & & & & $\begin{array}{c}-0.308 \\
(5.35)^{\star \star}\end{array}$ \\
\hline Universitaria completa & & & & $\begin{array}{l}-0.312 \\
(6.34)^{\star *}\end{array}$ \\
\hline Casado & $\begin{array}{l}0.049 \\
(1.45)\end{array}$ & $\begin{array}{l}0.048 \\
(1.42)\end{array}$ & $\begin{array}{c}0.05 \\
(1.46)\end{array}$ & $\begin{array}{l}0.023 \\
(0.81)\end{array}$ \\
\hline Diferencias salariales & $\begin{array}{c}0.362 \\
(23.83)^{\star *}\end{array}$ & $\begin{array}{c}0.351 \\
(17.70)^{\star *}\end{array}$ & $\begin{array}{c}0.394 \\
(13.05)^{\star *}\end{array}$ & $\begin{array}{c}0.351 \\
(12.05)^{\star *}\end{array}$ \\
\hline Población & $\begin{array}{c}0.014 \\
(3.79)^{\star *}\end{array}$ & $\begin{array}{c}0.011 \\
(5.02)^{\star *}\end{array}$ & $\begin{array}{c}0.021 \\
(2.82)^{\star *}\end{array}$ & $\begin{array}{l}0.001 \\
-1.94\end{array}$ \\
\hline Población2 & $\begin{array}{c}-0.0005 \\
(0.38)\end{array}$ & $\begin{array}{l}-0.0006 \\
(5.02)^{\star *}\end{array}$ & $\begin{array}{c}-0.0007 \\
(1.62)\end{array}$ & $\begin{array}{c}-0.0005 \\
(1.52)\end{array}$ \\
\hline Accidentes de tránsito & $\begin{array}{c}-0.003 \\
(8.01)^{\star *}\end{array}$ & & $\begin{array}{c}-0.003 \\
(6.01)^{\star *}\end{array}$ & $\begin{array}{c}-0.002 \\
(3.41)^{\star *}\end{array}$ \\
\hline Crímenes a la propiedad & $\begin{array}{r}-0.002 \\
(1.37)\end{array}$ & & $\begin{array}{l}-0.002 \\
(1.07)\end{array}$ & $\begin{array}{c}-0.009 \\
(4.89)^{\star *}\end{array}$ \\
\hline Violencia física a personas & $\begin{array}{c}-0.002 \\
(3.05)^{\star *}\end{array}$ & & $\begin{array}{l}-0.0003 \\
(2.90)^{\star \star}\end{array}$ & $\begin{array}{l}-0.0008 \\
(6.33)^{\star *}\end{array}$ \\
\hline Residuo Fiscal & & $\begin{array}{c}0.0015 \\
(8.16)^{\star *}\end{array}$ & $\begin{array}{c}0.0001 \\
(6.53)^{\star *}\end{array}$ & $\begin{array}{c}0.0001 \\
(4.98)^{\star *}\end{array}$ \\
\hline Gastos Educación & & $\begin{array}{l}-0.0001 \\
(4.04)^{\star *}\end{array}$ & $\begin{array}{c}-0.0001 \\
(1.33)\end{array}$ & $\begin{array}{l}-0.0002 \\
(3.69)^{\star *}\end{array}$ \\
\hline Programas de empleo y desempleo & & $\begin{array}{l}0.020 \\
(0.96)\end{array}$ & $\begin{array}{l}0.015 \\
(1.31)\end{array}$ & $\begin{array}{l}0.020 \\
(0.11)\end{array}$ \\
\hline Gastos en vivienda pública y urbanismo & & $\begin{array}{c}0.014 \\
(3.02)^{\star *}\end{array}$ & $\begin{array}{c}0.016 \\
(5.21)^{\star *}\end{array}$ & $\begin{array}{c}0.03 \\
(7.61)^{\star *}\end{array}$ \\
\hline Caminos sin pavimentar & & & & $\begin{array}{c}-0.001 \\
(3.28)^{\star *}\end{array}$ \\
\hline Precipitaciones promedio annual & & & & $\begin{array}{c}0.005 \\
(1.2)\end{array}$ \\
\hline Temperatura promedio anual & & & & $\begin{array}{l}0.004 \\
(0.28)\end{array}$ \\
\hline Recursos turísticos & & & & $\begin{array}{c}0.041 \\
(33.15)^{\star *}\end{array}$ \\
\hline Constante & $\begin{array}{c}-2.506 \\
(13.43)^{\star *}\end{array}$ & $\begin{array}{c}-2.639 \\
(14.10)^{* *}\end{array}$ & $\begin{array}{c}-2.57 \\
(13.68)^{* *}\end{array}$ & $\begin{array}{c}-1.72 \\
(9.03)^{\star *}\end{array}$ \\
\hline $\begin{array}{l}\text { Nro Observaciones } \\
\text { Pseudo R2 }\end{array}$ & $\begin{array}{l}27712 \\
0.2496 \\
\end{array}$ & $\begin{array}{l}27712 \\
0.2492 \\
\end{array}$ & $\begin{array}{l}27712 \\
0.2502 \\
\end{array}$ & $\begin{array}{l}27726 \\
0.2713 \\
\end{array}$ \\
\hline
\end{tabular}

Robust $\mathrm{z}$ statistics in parentheses- * significant at 5\%; ** significant at $1 \%$ Fuente: estimación propia sobre la base de la EPH, Mayo 2003. 


\section{CONCLUSIONES}

Las tasas de migración internacional e interna en Argentina, ubican al país entre los de mayor movilidad poblacional. Si bien las tasas de migración han variado en respuesta a distintos fenómenos históricos según las épocas, el país se caracteriza por experimentar altas tasas migración y redistribución espacial de su población. De acuerdo al último Censo de Población, los migrantes extranjeros representan apenas el 5\% del total de la población, mientras que los migrantes internos representan alrededor del $20 \%$ de la población. Entre las provincias con mayores tasas de inmigración se encuentran las provincias de Tierra del Fuego, Santa Cruz, San Luis, Corrientes, Neuquén y la Rioja. No sorpresivamente las provincias con mayores tasas de emigración son también Tierra del Fuego, Capital Federal, Santa Cruz y Río Negro y Corrientes, lo cual indica que los mayores intercambios poblacionales se dan entre las provincias menos pobladas (las provincias de la región patagónica).

Al estudiar las características de la población migrante, se observa una mayor proporción de mujeres y de jóvenes y adultos entre los migrantes internos, decreciendo la probabilidad de migrar entre las personas de mayor edad. También se observa en nuestro país, un menor nivel educativo entre los migrantes internos, respecto de la población no migrante o nativa. Aunque como se demostró existen importantes diferencias entre regiones, con una mayor migración de personas con mayor educación en la región Patagónica, NOA y NEA. En cuanto a los niveles de ingreso, son mayores para los no migrantes que para los migrantes internos. Sin embargo, si el análisis se realiza por región geográfica, lo que se observa es que a excepción del Gran Buenos Aires, el ingreso promedio de los migrantes internos es superior al de los no migrantes. En cuanto a la situación de pobreza, el porcentaje de población que vive en situación de pobreza, es menor entre los migrantes internos y mayor para la población nativa no migrante.

Los resultados de las estimaciones de la probabilidad de ser migrante interno, indican que no hay diferencias de género en la probabilidad de ser migrante interno y que la propensión de migrar es mayor entre las personas jóvenes y adultas, disminuyendo entre las personas de mayor edad. También se observo que las personas menos educada que tienen una mayor propensión a migrar. En los modelos estimados, la variable correspondiente al estado civil de las personas (Casado), sin embargo, los resultados indican que la probabilidad de migrar hacia otra provincia, disminuye cuando hay hijos menores de edad presentes en el hogar. Cuando se incorporan dummies regionales, respecto del GBA, la probabilidad de ser migrante interno es menor en las regiones Pampeana, NOA, NEA y Cuyo y solo es mayor para la región Patagónica.

Las diferencias en los salarios entre regiones tienen una fuerte influencia en las decisiones de migración de las personas. Así como también los beneficios derivados de la aglomeración, dado que se observa una preferencia de las personas por migrar a las provincias con mayor población o grandes centros urbanos. En cambio, las variables relacionadas con la seguridad de las regiones, como los accidentes de tránsito, como los crímenes a la propiedad o la violencia física hacia las personas afectan negativamente la decisión de migrar a una región. Las políticas públicas, a través de los gastos en educación, programas de empleo y seguros de desempleo, así como también los programas de vivienda pública provinciales influencian positivamente el movimiento migratorio hacia esas provincias. El residuo fiscal per capita de cada provincia, también influencia positivamente la probabilidad de migrar.

Las variables relacionadas con características de las regiones, como variables climáticas, no afectan las decisiones de re-localización de la población al interior de nuestro país. Si tienen un efecto positivo en las decisiones de migración, el grado de urbanización de las provincias, y los recursos naturales y turísticos que abundan en cada una de ellas. 


\section{BibLIOGRAFÍA}

Borjas, G.:(2001): “Does Immigration Grease the Wheels of the Labor Market?" Brookings Papers on Economic Activity.

Borjas, G., R. Freeman, and L. Katz (1999):"Searching for the Effect of Immigration on the Labor Market," American Economic Review Papers and Proceedings.

Celuba R. (1979): "Voting with one`s feet. A Critique of the Evidence". Regional Science and Urban Economics.

Carlsen, F. (2001): "Migration, Local Fiscal Variables and Local Economic Conditions". Center for Economic Studies \& Ifo Institute for Economic Research.

Clark, D. and Hunter W. (1992): "The Impact of Economic Opportunity, Amenities and Fiscal Factors on Age-Specific Migration Rates. Journal of Regional Science.

Courchene, Thomas J. (1978) 'The transfer system and regional disparities: A critique of the Status Quo,' in Canadian Confederation at the Crossroads: The Search for a Federal Provincial Balance, ed. Michael

Courchene, Thomas J. (1970): 'Interprovincial migration and economic Adjustment,' Canadian Journal of Economics 3, 550-76.

Day, Kathleen M. (1992) 'Interprovincial migration and local public goods.' Canadian Journal of Economics 25, 123-44.

Day, K. and Stanley W. (1994) 'Internal migration and public policy: An introduction to the issues and a review of empirical research on Canada.' In Issues in the Taxation of Individuals, ed. Allan Maslove (Toronto: University of Toronto Press, 3-61).

Day, K. and Stanley W. (2001) 'Interregional Migration and Public Policy in Canada: An Empirical Study.' (Ottawa: Human Resources Development Canada and Statistics Canada).

FIEL (1999): "La Distribución del Ingreso en Argentina"

Greenwood, M. J. (1985). Human Migration: Theory, Models, and Empirical Studies. Journal of Regional Science.

Greenwood, M. J., and Hunt, G. L. (1989). Jobs versus Amenities in the Analysis of Metropolitan Migration. Journal of Urban Economics.

Hanson G. "International Migration, Self-Selection, and the Distribution of Wages: Evidence from Mexico and the United States"

Katz (1998): “Gender and the Demographic Determinants of Migration in Ecuador".

Navarro, A. y Mendez F, (2001): "Desigualdades Urbanas y Migraciones Internas en Argentina" Universidad Austral.

Mincer, J. (1978). Family Migration Decisions. Journal of Political Economy. 
Plane, D. A. (1993). Demographic Influences on Migration. Regional Studies, 27(4), 375383.

Porto A. y Ennis, H.: "Decisiones de localización y lugar de trabajo".

Porto Natalia (2004):"Una aproximación al contenido factorial dominante de los recursos turísticos en Argentina". Universidad Nacional de La Plata

Richard H. Steckel: "Household Migration, Urban Growth, and Industrialization: The United States, 1850-1860"

Rosenbloom and Sundstrom. "The Decline and Rise of Interstate Migration in the United States: Evidence from the IPUMS, 1850-1990"

Shawn Kantor: "Do Federal Programs Affect Internal Migration? The Impact of New Deal Expenditures on Mobility During the Great Depression".

Card and E. DiNardo: "Do Immigrant Inflows Lead to Native Outflows?"

Stephen J. Trejo: "Self-Selection and Internal Migration in the United States"

Swarnjit S. Arora: Migration Flows and Their Determinants: A Comparative Study of Internal Migration in Italy and the U.S.A."

Sjaastad (1962) “The Costs and Returns of Human Migration”. Journal of Political Economy

Wildasin D. (2001): "Liberalization and the spacial allocation of population in developing and transitions countries"

Williamson J.(1989): "What Fundamentals Drive World Migration?", National Bureau of Economic Research 


\section{APÉNDICE}

Cuadro A.1

Bloque de Migraciones- EPH (Para toda la población encuestada)

\begin{tabular}{|c|c|}
\hline Pregunta & Descripción \\
\hline$\overline{\mathrm{p} 59}$ & $\begin{array}{l}\text { Donde nació: } \\
\qquad \begin{aligned} 1 & =\text { en esta ciudad } \\
2 & =\text { en otro lugar de esta Provincia } \\
3 & =\text { en otra Provincia } \\
4 & =\text { en otro país }\end{aligned}\end{array}$ \\
\hline P59COD & Código de provincia o país \\
\hline P59_4 & Año de llegada al país para $p 59=4$ \\
\hline P60 & $\begin{array}{l}\text { Ha vivido fuera de esta ciudad (área de relevamiento) más de } 6 \text { meses: } \\
\qquad \begin{array}{l}1=s i ́ \\
2=\text { no }\end{array}\end{array}$ \\
\hline P61 & $\begin{array}{l}\text { ¿Dónde? (anotar ultimo lugar) } \\
\qquad \begin{array}{l}2=\text { en otro lugar de la provincia } \\
3=\text { en otra provincia } \\
4=\text { en otro país }\end{array}\end{array}$ \\
\hline P61COD & Código de provincia o país \\
\hline P62 & Desde cuando esta viviendo en forma continua en esta ciudad (años) \\
\hline $\mathrm{P} 62 \mathrm{M}$ & Desde cuando esta viviendo en formacontinua en esta ciudad (meses) \\
\hline
\end{tabular}

Fuente: Encuesta Permanente de Hogares (EPH), INDEC.

Cuadro A.2

Población total, crecimiento y densidad poblacional

Países seleccionados de América Latina y el Caribe

\begin{tabular}{lrrcc}
\hline \hline \multirow{1}{*}{ País } & \multicolumn{2}{c}{$\begin{array}{c}\text { Población Total } \\
\text { (en miles) }\end{array}$} & $\begin{array}{c}\text { Crecimiento } \\
\text { porcentual }\end{array}$ & $\begin{array}{c}\text { Densidad } \\
\text { poblacional }\end{array}$ \\
\cline { 2 - 3 } & \multicolumn{1}{c}{1960} & \multicolumn{1}{c}{2000} & \\
\hline Argentina & 20,013 & 36,260 & 0.45 & 10 \\
Bolivia & 3,351 & 8,317 & 0.60 & 8 \\
Brasil & 72,742 & 173,858 & 0.58 & 21 \\
Chile & 7,643 & 15,412 & 0.50 & 20 \\
Colombia & 16,857 & 42,120 & 0.60 & 41 \\
Costa Rica & 1,334 & 3,929 & 0.66 & 77 \\
Ecuador & 4,439 & 12,306 & 0.64 & 44 \\
El Salvador & 2,578 & 6,280 & 0.59 & 303 \\
Guatemala & 4,139 & 11,166 & 0.63 & 100 \\
Honduras & 1,894 & 6,424 & 0.71 & 57 \\
Mexico & 36,940 & 100,088 & 0.63 & 51 \\
Nicaragua & 1,617 & 4,959 & 0.67 & 41 \\
Paraguay & 1,842 & 5,470 & 0.66 & 14 \\
Peru & 9,931 & 25,952 & 0.62 & 20 \\
Uruguay & 2,538 & 3,342 & 0.24 & 17 \\
Venezuela & 7,579 & 24,418 & 0.69 & 28 \\
\hline
\end{tabular}

$(*)$ Cifras correspondientes al año 2000.

Fuente: Institutos Nacionales de Estadística y Censo. 
Cuadro A.3

Distribución de la población argentina por provincias, según censos nacionales

\begin{tabular}{|c|c|c|c|c|c|c|c|c|}
\hline Provincias & 1895 & 1914 & 1947 & 1960 & 1970 & 1980 & 1991 & 2001 \\
\hline Buenos Aires & 921,168 & $2,066,948$ & $4,273,874$ & $6,766,108$ & $8,774,529$ & $10,865,408$ & $12,594,974$ & $13,818,677$ \\
\hline 19 Partidos (2) & 117,763 & 458,217 & $1,741,338$ & $3,772,411$ & $5,380,447$ & $6,843,201$ & $7,969,324$ & $8,684,437$ \\
\hline Resto (2) & 803,405 & $1,608,731$ & $2,532,536$ & $2,993,697$ & $3,394,082$ & $4,022,207$ & $4,625,650$ & $5,142,766$ \\
\hline C. de Bs As & 663,854 & $1,575,814$ & $2,981,043$ & $2,966,634$ & $2,972,453$ & $2,922,829$ & $2,965,403$ & $2,776,138$ \\
\hline Catamarca & 90,161 & 100,769 & 147,213 & 168,231 & 172,323 & 207,717 & 264,234 & 334,568 \\
\hline Chaco & 10,422 & 46,274 & 430,555 & 543,331 & 566,613 & 701,392 & 839,677 & 984,446 \\
\hline hubut & 3,748 & 23,065 & 92,456 & 142,412 & 189,920 & 263,116 & 357,189 & 413,237 \\
\hline órdoba & 51,223 & 735,472 & $1,497,975$ & $1,753,840$ & $2,060,065$ & $2,407,754$ & $2,766,683$ & $3,066,801$ \\
\hline orrie & 9,618 & $347, \mathrm{C}$ & 525 & 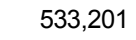 & 564, & 66 & 795,594 & 930,991 \\
\hline 00 & 292,019 & 5,373 & 787 & 805 & 811 & 908 & $1,020,257$ & $1,158,147$ \\
\hline rmosa & 4,829 & 19,281 & 1 & 178 & 234 & 29 & 398,413 & 486,559 \\
\hline juy & 49,713 & 77,511 & 166,700 & 241,462 & 302,436 & 410,008 & 512,329 & 611,888 \\
\hline Pampa & 25,914 & 101,338 & 169,480 & 158,746 & 172,029 & 208,260 & 259,996 & 299,294 \\
\hline Rioja & 69,502 & 79,754 & 110,746 & 128,220 & 136,237 & 164,217 & 220,729 & 289,983 \\
\hline endoza & 116,036 & 277,535 & 588,231 & 824,036 & 973,075 & $1,196,228$ & $1,412,481$ & $1,579,651$ \\
\hline isiones & 33,163 & 53,563 & 246 & 361, & 443, & 588,977 & 788,915 & 965,522 \\
\hline & 14,517 & 28,866 & & $10 s$ & 154 & 24 & 333 & 474,155 \\
\hline gro & 9,241 & 2,242 & 13 & 193 & 262 & 383 & 506,772 & 552,822 \\
\hline ta & 118, & 56 & 290 & 41 & 509 & 662 & 866,153 & $1,079,051$ \\
\hline$n$ & 1 & 52 & 261 & 352 & 384 & 465 & 528,715 & 620,02 \\
\hline an $\mathrm{L}$ & 81,450 & 116,266 & 165,546 & 174,316 & 183,460 & 214,416 & 286,458 & 367,933 \\
\hline anta Cruz & 1,058 & 9,948 & 42,880 & 52,908 & 84,457 & 114,941 & 159,839 & 196,958 \\
\hline anta $\mathrm{Fe}$ & 397,188 & 899,640 & $1,702,975$ & $1,884,918$ & $2,135,583$ & $2,465,546$ & $2,798,422$ & $3,000,701$ \\
\hline go. del E & 161,502 & 261,678 & 479,473 & 476,503 & 495,419 & 594,920 & 671,988 & 804,457 \\
\hline del Fuego (3) & 477 & 2,504 & 5,045 & 11,209 & 15,658 & 29.392 & 69,369 & 101,079 \\
\hline Tucumán & 215,742 & 332,933 & 593,371 & 773,972 & 765,962 & 972,655 & $1,142,105$ & $1,338,52$ \\
\hline Sin determinar (4) & 90,000 & 18,425 & - & - & - & - & - & - \\
\hline Total & 1,044,911 & $7,903,662$ & $15,893,811$ & $20,013,793$ & $23,364,431$ & $27,949,480$ & $32,615,528$ & $36,260,13 c$ \\
\hline
\end{tabular}

Nota: (2) Algunos componentes de estas dos jurisdicciones modificaron sus límites por lo cual los datos del 2001 no son estrictamente comparables con los de censos anteriores; (3) Para los censos de 1991 y 2001 se excluyen las Islas del Atlántico Sur; (4) En 1895 se estimaron 60.000 personas "sustraídas a la operación censal" y 30.000 indígenas; en 1914 se consignaron 18.425 habitantes como "población autóctona".

Fuente: Censos Nacionales de Población y Vivienda, INDEC.

Cuadro A.4

Evolución de la población total en censos nacionales, por regiones.

Total del país. Censos 1947-2001

\begin{tabular}{|c|c|c|c|c|c|c|c|c|c|c|c|c|}
\hline \multirow{2}{*}{ Región } & \multicolumn{2}{|l|}{1947} & \multicolumn{2}{|l|}{1960} & \multicolumn{2}{|l|}{1970} & \multicolumn{2}{|l|}{1980} & \multicolumn{2}{|l|}{1991} & \multicolumn{2}{|l|}{2001} \\
\hline & Población & $\%$ & Población & $\%$ & Población & $\%$ & Población & $\%$ & Población & $\%$ & Población & $\%$ \\
\hline GBA & $4,722,381$ & 29.7 & $6,739,045$ & 33.7 & $8,352,900$ & 35.8 & $9,766,030$ & 34.9 & $10,934,727$ & 33.5 & $11,460,575$ & 31.6 \\
\hline Pampeana & $6,690,340$ & 42.1 & $7,596,558$ & 38.0 & $8,573,450$ & 36.7 & $10,012,080$ & 35.8 & $11,471,008$ & 35.2 & $12,667,709$ & 34.9 \\
\hline Cuyo & $1,015,006$ & 6.4 & $1,350,739$ & 6.7 & $1,540,819$ & 6.6 & $1,876,622$ & 6.7 & $2,227,530$ & 6.8 & $2,567,607$ & 7.1 \\
\hline Nordeste & $1,316,204$ & 8.3 & $1,616,498$ & 8.1 & $1,807,855$ & 7.7 & $2,247,710$ & 8.0 & $2,822,599$ & 8.7 & $3,367,518$ & 9.3 \\
\hline Norœeste & $1,788,329$ & 11.3 & $2,201,242$ & 11.0 & $2,382,180$ & 10.2 & $3,012,387$ & 10.8 & $3,677,538$ & 11.3 & $4,458,470$ & 12.3 \\
\hline Patagonia & 361,551 & 2.3 & 506,457 & 2.5 & 705,000 & 3.0 & $1,032,619$ & 3.7 & $1,481,860$ & 4.5 & $1,738,251$ & 4.8 \\
\hline Total país & $15,893,811$ & 100.0 & $20,013,793$ & 100.0 & $23,364,431$ & 100.0 & $27,949,480$ & 100.0 & $32,615,528$ & 100.0 & $36,260,130$ & 100.0 \\
\hline
\end{tabular}

Fuente: Censos Nacionales de Población y Vivienda, INDEC. 
Cuadro $A 5$

Duración del desempleo según condición de migración y región geográfica

Total de aglomerados urbanos, Onda Mayo 2003.

\begin{tabular}{lccccccc}
\hline \hline \multirow{2}{*}{\multicolumn{1}{c}{ Condición de migración }} & \multicolumn{5}{c}{ Duración del desempleo } \\
\cline { 2 - 7 } & \multirow{2}{*}{ Total } & GBA & Pampeana & Cuyo NOA & Patagonia & NEA \\
\cline { 3 - 7 } & 8.41 & 1.03 & 0.89 & 0.35 & 0.48 & 0.36 & 0.29 \\
\hline Total & 8.64 & 1.06 & 0.92 & 0.36 & 0.44 & 0.37 & 0.28 \\
No migrantes & 7.46 & 0.93 & 0.73 & 0.33 & 0.65 & 0.33 & 0.32 \\
Migrantes internos & 5.07 & 0.62 & 0.76 & 0.49 & 0.73 & 0.31 & 0.45 \\
$\quad$ Migrantes de los últimos 5 años & 7.99 & 0.96 & 0.72 & 0.28 & 0.62 & 0.33 & 0.27 \\
\hline Migrantes de más de 5 años & &
\end{tabular}

Fuente: Estimación propia en base a la Encuesta Permanente de Hogares (EPH), INDEC.

Cuadro A6

Características habitacionales de los hogares, según condición de migración del jefe de hogar Total de aglomerados urbanos, Onda Mayo 2003.

\begin{tabular}{lccccc}
\hline & & \multicolumn{4}{c}{ Condición de migración } \\
\cline { 5 - 6 } Características habitacionales & $\begin{array}{c}\text { Pobación } \\
\text { Total }\end{array}$ & $\begin{array}{c}\text { No } \\
\text { migrantes }\end{array}$ & Total & Recientes & Más de 5 años \\
\hline Característica de la vivienda & & & & & \\
Propiedad de la vivienda & 0.70 & 0.71 & 0.68 & 0.27 & 0.72 \\
Nro de habitaciones & 2.87 & 2.88 & 2.86 & 2.48 & 2.90 \\
Personas por habitación & 1.37 & 1.36 & 1.39 & 1.30 & 1.40 \\
Vivienda precaria & 0.02 & 0.02 & 0.02 & 0.06 & 0.02 \\
Materiales precarios & 0.01 & 0.01 & 0.01 & 0.01 & 0.01 \\
Acceso a servicios en la viviendanyyyyy & & & & & \\
Agua potable & 0.99 & 0.99 & 0.99 & 0.98 & 0.99 \\
Electricidad & 1.00 & 1.00 & 1.00 & 1.00 & 1.00 \\
Baño en la vivienda & 0.88 & 0.89 & 0.85 & 0.90 & 0.84 \\
Cloacas & 0.61 & 0.64 & 0.54 & 0.76 & 0.52 \\
\hline
\end{tabular}

Fuente: Estimación propia en base a la Encuesta Permanente de Hogares (EPH), INDEC.

Cuadro $A 7$

Descripción de las variables. Valores promedios y desvio estándar.

Valores correspondientes al año 2003

\begin{tabular}{|c|c|c|c|}
\hline Variables & $\begin{array}{c}\text { Nro } \\
\text { Observaciones }\end{array}$ & Promedio & Desvio Estandar \\
\hline Migrantes internos & 27,739 & 0.28 & 0.45 \\
\hline Hombre & 27,739 & 0.46 & 0.50 \\
\hline Edad & 27,730 & 48.43 & 14.77 \\
\hline Años de educación & 27,720 & 9.54 & 4.19 \\
\hline Primaria incompleta & 27,734 & 0.14 & 0.35 \\
\hline Primaria completa & 27,734 & 0.29 & 0.46 \\
\hline Secundaria incompleta & 27,734 & 0.16 & 0.36 \\
\hline Secundaria completa & 27,734 & 0.20 & 0.40 \\
\hline Universitaria incompleta & 27,734 & 0.08 & 0.27 \\
\hline Universitaria completa & 27,734 & 0.13 & 0.33 \\
\hline Desocupados & 27,739 & 0.06 & 0.24 \\
\hline Casado & 27,735 & 0.69 & 0.46 \\
\hline Diferencias salariales & 27,739 & 3.25 & 0.78 \\
\hline Población & 27,739 & $3,862,815$ & $5,954,196$ \\
\hline Accidentes de tránsito & 27,739 & 283.93 & 364.83 \\
\hline Crímenes a la propiedad & 27,739 & 95,101 & 142,717 \\
\hline Violencia física a personas & 27,739 & 13,504 & 18,487 \\
\hline Residuo Fiscal & 27,739 & 565.25 & 913.79 \\
\hline Gastos Educación & 27,739 & 420.55 & 500.23 \\
\hline Programas de empleo y desempleo & 27,739 & 9.11 & 12.01 \\
\hline Gastos en vivienda pública y urbanismo & 27,739 & 38.72 & 50.05 \\
\hline Caminos sin pavimentar & 27,739 & 1,958 & 1,424 \\
\hline Precipitaciones promedio anual & 27,739 & 70.82 & 38.79 \\
\hline Temperatura promedio anual & 27,739 & 17.72 & 3.35 \\
\hline Recursos turísticos & 27,739 & 53.94 & 19.68 \\
\hline
\end{tabular}


